\title{
Abordagem Alternativa do Crescimento Agrícola: um Modelo de Dinâmica Evolucionária*
}

\author{
José Eustáquio Ribeiro Vieira Filho \\ Doutorando em Economia e Pesquisador do Núcleo de Economia Agrícola do IE-UNICAMP \\ Antônio Carvalho Campos \\ Departamento de Economia Rural - UFV \\ Carlos Mauricio de Carvalho Ferreira \\ Professor Titular da UFMG
}

Recebido: 30/4/2004 Aprovado: 31/5/2005

\section{RESUMO}

O artigo visa analisar a economia agrícola sob o enfoque da teoria evolucionária. O referencial teórico a ser objeto de estudo, contrário às concepçōes ortodoxas, baseia-se nos pressupostos de incertezas do ambiente, racionalidade limitada dos agentes, no desequilíbrio dinâmico e na instabilidade estrutural. No intuito de comparar a evolução tecnológica na agricultura com os padrões regionais dos sistemas agroindustriais brasileiros, procurou-se, de um lado, realizar, por meio de indicadores de localização e especialização, uma análise de concentração regional e, por outro, construir um Modelo Evolucionário de Crescimento Agrícola, aqui denominado MECA, que permite simular o provável comportamento da agricultura produtora de grãos. Dentro dessa orientação, foi possível identificar a região dinâmica agroindustrial bem como padrões de comportamento das mudanças técnicas na agricultura. Em um ambiente de competição tecnológica, o modelo mostra

\footnotetext{
* Os autores agradecem os pareceristas anônimos pelos comentários. Gostaríamos também de agradecer de forma especial a Rafael Giannetti Viotti no auxílio da programação matemática, sem a qual não seria possível apresentar os resultados preliminares do Modelo Evolucionário de Crescimento Agrícola - MECA. Embora significativo o seu auxílio, não nos eximimos da responsabilidade pelas interpretações feitas bem como pelos erros e omissões que por acaso estejam aqui contidos.
} 
que a competição pelos recursos produtivos nos complexos agroindustriais produtores de grãos leva à busca permanente de inovaçóes, caracterizando uma dinâmica evolucionária entre as atividades e uma maior concentração do capital setorial e regional.

Palavras-Chave | Teoria Evolucionária; Dinâmica Agrícola; Competição; Mudança Tecnológica

Códigos JEL | 01; 012;03;033

\section{ABSTRACT}

This paper aims at analyzing agricultural production under an evolutionary approach. The theoretical framework that supports the analysis is based on the assumptions of procedural and substantive uncertainties, bounded rationality, dynamic disequilibrium and structural instability. At first, specialization and localization indicators are determined in order to compare the Brazilian agricultural technology evolution within the interregional context. Later on, an Agriculture Evolutionary Growth Model, named MECA, has been constructed to simulate the probable behavior of agricultural grain producers and of any other commercial agricultural activity. In this way, it was possible to identify the agroindustrial dynamic region as well as the standard behavior of technical change in agriculture. In an environment of technological competition, the model shows that competition for productive resources in the agribusiness sector leads to a permanently search for innovations, characterizing an evolutionary dynamics among agricultural activities, and to a higher sectoral and regional concentration of capital.

KeYwords | Evolutionary Theory; Agricultural Dynamics; Competition; Technological Change

JEL CODES $\mid$ 01; 012;03;033 


\section{Introdução}

Este artigo visa abordar o crescimento da economia agrícola sob o enfoque da teoria evolucionária e, em paralelo, mostrar que a competição tecnológica na agricultura é comparável à competição biológica. Existem vários trabalhos voltados para a análise do setor industrial; porém, no que se refere à agricultura, o estudo aqui realizado é pioneiro na literatura econômica. O referencial teórico a ser estudado, contrário às concepções ortodoxas, baseia-se nas pressuposições de incertezas do ambiente, racionalidade limitada dos agentes, no desequilíbrio dinâmico e na instabilidade estrutural. Nessa perspectiva, podemse caracterizar os agentes dos sistemas de produção envolvidos como concorrentes schumpeterianos, que buscam permanentemente a diferenciação e a formulação de estratégias no intuito de obter vantagens competitivas, as quais possam proporcionar lucros de monopólios.

No intuito de comparar a evolução tecnológica na agricultura com os padrões regionais dos sistemas agroindustriais brasileiros, procurou-se, de um lado, realizar uma análise com métodos regionais e, por outro, construir um Modelo Evolucionário de Crescimento Agrícola, aqui denominado MECA, que possa simular o provável comportamento da agricultura produtora de grãos ou mesmo da agricultura de mercado, quer seja comparativamente entre regióes do País, quer seja entre as empresas do agronegócio, em uma mesma região. Desta maneira, foi possível identificar a região dinâmica agroindustrial, bem como padrões de comportamento das mudanças técnicas na agricultura. Em um ambiente de competição tecnológica, o modelo procura mostrar que a competição pelos recursos produtivos nos complexos agroindustriais produtores de grãos leva à busca permanente de inovações, caracterizando uma dinâmica evolucionária entre as atividades e uma maior concentração do capital setorial e regional.

O artigo está organizado em dois estudos paralelos autônomos, sendo o primeiro uma abordagem estática e o segundo uma análise dinâmica. É importante ressaltar que um não exclui o outro, mas que, pelo contrário, existem complementaridades entre si. No estudo regional, por meio de uma avaliação de indicadores econômicos, procura-se determinar padrões tanto da produção agrícola quanto da regionalização tecnológica, o que torna possível a identificação de regiōes dinâmicas e passivas em termos de desenvolvimento. 
Por exemplo, como será visto, nota-se um crescimento diferenciado da produção agrícola do Centro-Oeste brasileiro nos últimos anos, enquanto que nas regiōes Sudeste e Sul constatam-se quedas na participação produtiva. Além disso, verifica-se um comportamento relativo desfavorável da produção das regiōes Norte e Nordeste. Esta constatação do estudo regional é um fato (uma visão estática), já que se deveu apenas à observação empírica. Cabe à análise dinâmica dar sentido aos movimentos da reestruturação produtiva regional, ora explicando o motivo do crescimento regional diferenciado nos últimos anos, ora fazendo prognósticos quanto ao que poderá acontecer com a concentração produtiva, dada as características produtivas e tecnológicas regionais. Assim, entende-se que tanto a abordagem estática quanto a análise dinâmica são fundamentais para compreender o processo de crescimento agrícola.

Para tanto, cinco seções são apresentadas, além dessa breve introdução. A seção 2 apresenta a teoria evolucionária do crescimento econômico e os seus principais conceitos. A seção 3 expõe o Modelo Evolucionário de Crescimento Agrícola. A seção 4 aponta as mudanças estruturais na agricultura brasileira, fazendo análise e discussão dos resultados empíricos, no que se refere à regionalização da produção de grãos bem como do progresso técnico e sua alocação geográfica. A seção 5 realiza uma simulação dos comportamentos tecnológicos das atividades produtivas regionais. Por fim, apresentam-se as principais conclusões do modelo evolucionário de crescimento da agricultura e suas interações com as questões da concentração setorial e regional.

\section{Teoria evolucionária do crescimento econômico}

A teoria evolucionista foi apresentada, originalmente, em meados do século XIX, para tentar explicar a origem e a evolução das espécies. Na realidade, Charles Robert Darwin ${ }^{1}$ procurou evidenciar, de forma metódica, a evolução progressiva das espécies, a seleção natural e a sobrevivência do mais apto, sendo a origem das espécies descendente de um ancestral comum.

Darwin não só citou como também afirmou que ninguém como o economista Thomas Robert Malthus, no Ensaio sobre a População, de 1798, transmitia

\footnotetext{
A teoria evolucionista, a qual foi publicada pela primeira vez em 1859, com o título original em inglês $O n$ the $O$ rigin of Species by Means of Natural Selection, pôde influenciar não somente a biologia, mas também outras áreas, inclusive a economia.
} 
de modo tão singular a luta pela existência das espécies. Neste ensaio, colocouse a polêmica descrição da humanidade que deveria lutar pelos recursos alimentares disponíveis em busca de sua sobrevivência. A tese malthusiana era de que a população cresceria à taxa superior à da produção de alimentos e dos meios de subsistência, o que conduziria ao fim inevitável do homem e a pobreza generalizada.

As evoluções orgânica e social eram, para Darwin, uma fusão do domínio entre a competição e a seleção malthusianas. Quanto maior fosse a desproporção entre o crescimento da população e dos alimentos, mais intensas seriam a miséria e a fome seguidas de pestes, epidemias e guerras, o que era uma tentativa natural de reequilibrar temporariamente o ambiente. A diminuição dos alimentos constituiria, então, em uma forma de frear o crescimento demográfico. Assim, "Darwin percebeu que uma luta idêntica ocorria em toda a natureza e compreendeu que essa luta poderia ser transformada em uma força verdadeiramente criativa” (Desmond \& Moore, 2000:284).

É importante registrar que as estatísticas não confirmaram o pensamento malthusiano, seja no crescimento da população ou mesmo da produção de alimentos. De um lado, apenas para exemplificar, o uso de métodos anticoncepcionais, já consagrados no final do século XIX, propiciou uma redução significativa do crescimento populacional. Por outro, a introdução de técnicas mais refinadas de cultivo e tratamento do solo bem como as descobertas de adubos químicos e de grãos híbridos permitiram um notável crescimento da produtividade agrícola. $^{2}$

Todavia, sob o ponto de vista de Joseph Alois Schumpeter, aquele que viria a ser referência nos estudos econômicos evolucionários, a influência econômica ao pensamento darwiniano não foi tão significativa quanto aparenta ser. A este respeito, quanto à inspiração de Darwin pela teoria da população de Malthus, tem-se o seguinte comentário;

“(...) Parece muito arriscado, para dizer a verdade, discordar da afirmação de uma pessoa sobre o seu próprio processo mental. Todavia, acontecimentos ou sugestóes bastante insignificantes podem dar lugar a uma determinada

2 É importante observar que alguns dos avanços tecnológicos na agricultura foram desenvolvidos somente após a publicação da última e sexta edição do ensaio de Malthus, em 1826, não havendo, portanto, tempo suficiente para realizar modificações no cerne da tese original. 
corrente de pensamento; o próprio Darwin não incluiu a obra de Marx em seu Historical Sketch já mencionado, embora a ela se referisse em sua introdução; e a simples afirmação de que 'nascem mais individuos de cada espécie do que podem, provavelmente, sobreviver' [o que, ademais, é um malthusianismo duvidoso], nada mais é, em si mesmo, do que uma trivialidade. Receio, portanto, que o serviço prestado pela Economia à evolução da doutrina darwiniana guarde uma certa analogia com o serviço prestado a Roma pelos célebres gansos do Capitólio" (Schumpeter, 1964:81).

Segundo Schumpeter (op. cit), a única teoria econômica genuinamente evolucionista, na grandeza de sua concepção, que o século XIX produziu, foi a análise proposta por Karl Marx. A visão de uma evolução imanente do processo econômico, em que se tenha uma acumulação capitalista, a qual produz uma situação social insustentável, proporciona o surgimento de uma outra forma de organização social. Dessa maneira, não descartando as ambições filosóficas da abordagem marxista, tanto o materialismo histórico quanto o determinismo histórico são mais do que um simples instrumental analítico dos fatos. Porém, é importante compreender, a fim de evitar confusões, que o evolucionismo marxista nada tinha a ver com o evolucionismo darwiniano, e nenhum dos dois empresta qualquer apoio ao outro. Nesse sentido, a influência darwiniana na economia deu-se de fato somente no século posterior.

No cenário intelectual do período seguinte, após a difusão da proposta darwiniana, a sociedade passa a ser entendida como um sistema "orgânico" e não "mecânico", uma analogia aos organismos biológicos. Assim, pode-se perfeitamente trabalhar com um enfoque evolucionário próprio da economia, em que as firmas competem entre si, e que apenas as mais adaptadas sobreviverão por meio de um processo seletivo no ambiente de mercado. No campo da história econômica, uma das principais tarefas intelectuais tem sido entender de que forma o complexo das mudanças tecnológicas e das organizações econômicas afetam o curso da humanidade. Desse modo, como apresentado por Burnham (1997), Darwin pode ajudar a economia, ou melhor, a genética evolucionária auxilia no entendimento dos fatos e comportamentos econômicos.

A influência darwiniana foi tão forte que o transbordamento para outros ramos do saber foi inevitável, notadamente no desenvolvimento das teorias 
econômicas associadas ao crescimento. Embora, no âmbito do mainstream da ciência econômica, tenham se desenvolvido teorias de crescimento econômico, é preciso incorporar ao debate, sob a perspectiva não-ortodoxa, elementos que possam ampliar o poder explicativo dessas teorias. Nos modelos ortodoxos, a questão tecnológica é tratada como um resíduo (uma variável exógena), não sendo, portanto, alvo de discussão a origem e a dinâmica do desenvolvimento tecnológico. ${ }^{3}$ Conforme Nelson e Winter (1982:276),

“(...) In recent years there has developed a small class of models attempting to formalize Schumpeter's contribution but preserving some variant of the orthodox premises of profit maximization and equilibrium. Although these models have yielded some illuminating insights, they ignore essential aspects of Schumpeterian competition - the fact that there are winners and losers and that the process is one of continuing disequilibrium. An evolutionary analysis seems required if the model is to recognize those facts."

No enfoque mais generalizado, a corrente do pensamento evolucionário encontra suas raízes no campo biológico, no entendimento da evolução das espécies proposta por Darwin. Todavia, no foco econômico, a concepção evolutiva da economia advém desde os referidos trabalhos de Malthus e Marx até as escolas de Veblen, Schumpeter e mesmo Keynes, os quais anteciparam muito das idéias contemporâneas da teoria evolucionária do crescimento econômico. A idéia de que a competição de mercado é análoga à competição biológica e que os negócios das firmas devem passar por um teste de sobrevivência imposto pelo mercado tem sido parte de toda a discussão da concepção evolutiva da economia. Porém, a primeira contribuição mais firme do

3 Em artigo clássico publicado em 1956, "A contribution to the theory of economic growth", Robert M. Solow, Prêmio Nobel de Economia em 1987, procurou criar as bases para uma discussão teórica do desenvolvimento econômico por meio de um modelo de crescimento. No ano seguinte, em 1957, elaborou artigo intitulado "Technical change and the aggregate production function" que explicava como a poupança, o crescimento demográfico e o progresso tecnológico afetavam o aumento do produto. Neste último trabalho, Solow (1968:179) apresenta como uma de suas principais conclusões a relativa importância atribuída à mudança tecnológica, sendo que "Gross output per man hour doubled over the interval, with 87 1 1 2 per cent of the increase attributable to technical change and the remaining 12 1/2 per cent to increased use of capital". Embora reconhecendo a importância da questão tecnológica, a explicação do crescimento econômico é dada de forma estática pelos fatores produtivos capital e trabalho, sendo residual (ou mesmo uma "medida da ignorância humana") a determinação do aumento produtivo resultante da tecnologia. Se a mudança tecnológica é a variável que explica em sua maior parte as variações no produto, a produtividade do capital não pode ser considerada como um resíduo, mas sim determinada de forma endógena em qualquer modelo de crescimento. 
ponto evolucionário remonta ao artigo de Alchian (1950), "Uncertainty, Evolution and Economic Theory". ${ }^{4}$

Posteriormente, de uma maneira mais sistematizada, é a corrente evolucionária identificada por Nelson e Winter (1982) que introduz as noções de busca (search) por inovaçôes, a partir das estratégias empresariais, e pela seleção (selection) destas mesmas inovaçōes, pelo ambiente de mercado. ${ }^{5} \mathrm{O}$ processo dinâmico de concorrência, por parte das empresas, é definido pelas estratégias inovativas e por critérios de eficiência produtiva. Por outro lado, no âmbito do mercado, tal processo é estabelecido por pressōes competitivas (ameaça à entrada) e fatores favoráveis à concorrência e à competitividade. Desde a sistematização de uma teoria da economia evolucionária no início da década de 1980, vários autores procuraram seguir a abordagem difundida por esta corrente. Dentre esses autores, destacamse os trabalhos de Dosi (1984), Dosi et al. (1988), Saviotti e Metcalfe (1991) e Possas et al. (2001).

A noção ortodoxa do pensamento econômico associa concentração industrial a uma falha no processo de competição do mercado, por um número reduzido de grandes firmas que atuam de forma interdependente no que se refere à tomada de decisões sobre os preços, a produção e outras questôes de interesse mútuo. A distorção no processo competitivo deve-se à alocação subótima dos recursos, uma vez que os preços estabelecidos tendem a ser superiores ao preço de equilíbrio do mercado com um número elevado de firmas (Kon, 1999).

Neste artigo, pretende-se enfocar, como sugerido por Possas (2002b), a questão da concorrência schumpeteriana, a qual se insere numa visão dinâmica e evolucionária do funcionamento da economia capitalista. Para entender o crescimento diferenciado do agronegócio brasileiro e sua concentração regional é necessário buscar microfundamentos que possam determinar as trajetórias do desenvolvimento, destacando-se os fatores endógenos explicativos da evolução econômica. Como fundamentos teóricos, no tocante à análise proposta, é importante rejeitar os pressupostos de equilíbrio do mercado e de racionalidade substantiva, na qual os agentes maximizam a função-objetivo (utilidade, lucros)

4 Em suma, a influência de Alchian tem sido notada em uma série de áreas da economia, como a competição econômica, a organização industrial e a teoria monetária e financeira. Para uma discussão da abrangência e importância do trabalho de Alchian, ver a coletânea de artigos em Lott Jr. (1997).

5 Esta corrente pode ser identificada por neo-schumpeteriana, visto que retoma o debate acerca das inovações tecnológicas e incorpora, ao mesmo tempo, o paradigma evolucionário em suas análises. 
e estabelecem uma consistência de preferências individuais. A teoria do desenvolvimento econômico a ser objeto de estudo deve estar, portanto, relacionada com os pressupostos teóricos de incerteza forte, de instabilidade estrutural e desequilíbrio dinâmico, distanciando-se das pressuposiçôes clássicas de expectativas racionais e de equilíbrio.

É claro que o relato acerca do conceito de competição abrange dois conflitos de idéias, competição como estrutura e competição como um processo. Segundo Metcalfe et al. (2003:10),

"In the first, competition is a statement about the structure of the industry not a statement of the characteristics of the individual firms that may as well be treated as identical. In the second it is the properties of the firms that matter crucially in determining how much rivalry exists and rivalry is measured by the changes in the positions of the different firms. How these differences are resolved into patterns of structural change depends on the coordinating role of the relevant markets."

É essa perspectiva de desenvolvimento que foi trabalhada. Na visão evolucionária, a intensidade da competição é mensurada pelas mudanças dadas pelo mercado e pelas posiçóes relativas dos produtores rivais. Nos mercados em que as participações são estáveis, a disputa por vantagens competitivas pode não existir. Então, pode-se dizer que as participações relativas são mudadas e a taxa da mudança estrutural proporciona um cálculo da intensidade de competição.

A sobrevivência da firma no ambiente competitivo está associada à capacidade de aprendizado em alterar as suas rotinas e manter, simultaneamente, as suas metas, seja, por exemplo, via aumento de participação de mercado ou de elevação da taxa de lucro. A partir do momento em que as metas não são alcançadas, a firma deverá adotar novos comportamentos estratégicos, os quais dependem não só de informações disponíveis no mercado, como também da criação de novos conhecimentos. Ao contrário do que a teoria convencional postula, as firmas podem neste processo incorrer em erros sistemáticos, que decorrem do fato das escolhas estarem diante de um contexto de incerteza. Há tanto as incertezas decorrentes da ausência de informaçôes (substantive uncertainty), quanto às limitações do mecanismo de aprendizado dos agentes (procedural uncertainty). 
Em resposta ao cenário de incerteza, os agentes são levados a adotar rotinas e regras estáveis de decisão, no intuito de orientar as suas ações (Dosi \& Egidi, 1991; Crocco, 1999; Cerqueira, 2000).

As decisões econômicas que envolvem a produção presente e o investimento futuro ocorrem num ambiente de elevada incerteza. As firmas são rivais e produzem em um mercado competitivo. $O$ processo de produção dá-se ao longo do tempo e requer a utilização de novas tecnologias, as quais implicam em imobilização parcial de capital. O princípio da demanda efetiva está associado ao comportamento da economia, mediante o gasto de consumo e o dispêndio de investimento. De um lado, o gasto em consumo seria uma função estável da renda. Por outro, o dispêndio em investimento seria uma função instável da taxa de juros e da taxa de retorno, haja visto que a taxa de retorno depende das expectativas de longo prazo. É esta dependência em relação às decisões futuras que cria, no curto prazo, as flutuações econômicas, notadamente ao enfocar os investimentos (variável decisiva nas estratégias inovadoras).

No intuito de adaptar o instrumental analítico, a utilização dos pressupostos heterodoxos na agricultura é uma forma de transpor a idéia clássica de que a firma agrícola não poderia obter rendimentos marginais crescentes. Nesse sentido, foram trabalhadas as correntes evolucionárias neo-shumpeterianas de uma abordagem microdinâmica das firmas, as quais se associam aos resultados do princípio da demanda efetiva, diretamente ligada à volatilidade e instabilidade do investimento. Sob condiçôes de incerteza e complexidade das decisões dos agentes, deve-se enfocar o conceito de racionalidade limitada (bounded rationality), uma vez que o ambiente restringe a maximização econômica. A limitação decorre da complexidade do ambiente que envolve as decisões dos agentes, que não conseguem atingir a racionalidade plena. De acordo com Simon, ${ }^{6}$ citado por Williamson (1993:92), “(...) human agents are assumed to be intendedly rational, but only limitedly so (...)”. Quanto ao processo de decisão racional dos agentes, a limitação da racionalidade permite conciliar a lógica da racionalidade instrumental com a questão da incerteza forte.

Segundo Possas (2002a:419), "A concorrência schumpeteriana caracteriza-se pela busca permanente de diferenciação por parte dos agentes, por meio de estratégias deliberadas, tendo em vista a obtenção de vantagens competitivas

6 Simon, H. (1947), Administrative Behavior, 2.ed., Nova York: Macmillan, 1961. 
que proporcionem lucros de monopólio (...)”. Como num processo evolutivo, a concorrência implica em um surgimento endógeno de diversidade no sistema econômico, de variadas formas ou dimensões. A concorrência mais tradicional se dá via preço. Mas, o ambiente competitivo pode se formar pela diferenciação do produto e por inovações no sentido amplo (novos produtos e processos, mudança na organização produtiva, novas tecnologias e novos mercados). Portanto, é no intuito de buscar lucros extraordinários que o investimento cria uma dinâmica própria, a ponto de gerar inovações e maior competição.

Conforme a Figura 1, apresenta-se o paradigma evolucionário como sendo uma relação conjunta de um processo dinâmico e em desequilíbrio com os mecanismos seletivos do mercado. Dado que os processos são não-ergódicos, é impossível formar expectativas racionais quanto a um estado estacionário. O conhecimento passado não é suficiente para prever um futuro dinâmico. A mudança permanente nos processos econômicos torna inviável uma decisão ótima. Conseqüentemente, o comportamento observado dos agentes seria não-uniforme na tentativa de realizar um ajuste imediato e sistemático a cada nova informação, comportamento de "satisfying".

FIGURA 1

Paradigma evolucionário como a união de um processo dinâmico e em desequilíbrio com a seleção natural

Dinâmica e desequilíbrio

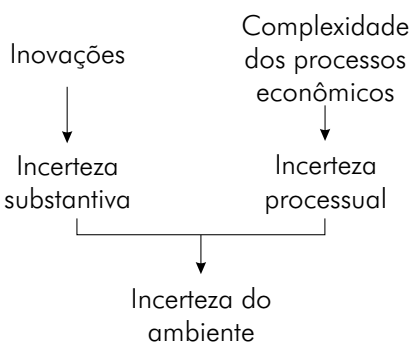

$(+)$

Adoção de regras

comportamentais

$(=)$

Regularidades no processo de decisão dos agentes
Seleção natural

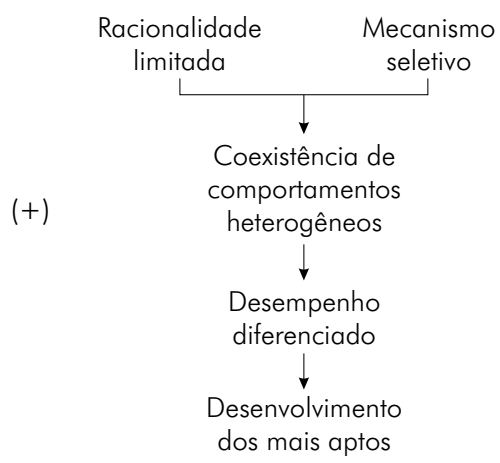


Se for afirmado que os agentes são dotados de uma racionalidade limitada, pode-se, assim, imaginar um comportamento regular dos agentes derivado de uma situação de desequilíbrio. Diante das incertezas substantiva e processual, a adoção de regras comportamentais cria regularidades no processo de decisão dos agentes. É exatamente por estas regularidades que se permite a aplicação do método científico de análise na existência de incertezas. Todavia, dinâmica e desequilíbrio não são condições suficientes para determinar o paradigma evolucionário. Caso não exista um mecanismo de seleção, mesmo que o sistema seja heterogêneo, a evolução seria impossível. Desta forma, o paradigma evolucionário necessita não só de um processo dinâmico e desequilibrado, mas também de um mecanismo seletivo de mercado. É por meio deste mecanismo que se pode identificar o desenvolvimento dos agentes mais aptos. $\mathrm{Na}$ ausência deste mecanismo de seleção, não há organização para o sistema como um todo (Cavalcanti Filho, 2002).

\section{Modelo Evolucionário de Crescimento Agrícola - MECA}

Seguindo a tendência da modelagem evolucionária contemporânea, ${ }^{7}$ foi utilizada uma adaptação do modelo seminal apresentado por Nelson e Winter (1982). Para essa adaptação, procura-se integrar uma análise setorial tanto no esforço inovativo quanto no processo de aprender-fazendo (learning by doing), ${ }^{8}$ acrescentando características específicas do mercado agrícola. Para tanto, foram analisadas as trajetórias randômicas futuras e determinadas as variáveis de produção, preços e lucros, bem como as decisões de investimento (havendo restrições financeiras a este investimento) e os procedimentos randômicos de busca tecnológica, seja por imitação ou inovação.

Para a agricultura, optou-se por definir dois tipos de capital: (i) estoque, e (ii) fluxo. O primeiro diz respeito àquele que é datado até um momento $t$ e que possui uma menor taxa de depreciação. Como exemplo, têm-se as benfeitorias, máquinas e equipamentos agrícolas. Já o segundo, no presente artigo, procura especificar aquele tipo de capital que é consumido quase que

\footnotetext{
Para uma seleção de artigos referentes à inovação, à organização e à dinâmica econômica, ver Dosi (2000).

8 Osforço inovativo é analisado por Nelson \& Winter (1982) e os fundamentos do processo de aprendizado por Silverberg et al. (1988), apud Possas et al. (2001).
} 
inteiramente (efeito residual) no processo produtivo em um dado período de plantio e colheita. $\mathrm{O}$ exemplo neste caso pode ser descrito pelos fertilizantes, defensivos e sementes.

Com o maior uso de implementos e máquinas agrícolas, seguindo a taxonomia determinada por Pavitt (1984), a agricultura pode ser considerada como sendo um setor dominado pelos fornecedores (supplier dominated). Dessa maneira, trabalha-se com a tecnologia embarcada. A relação do setor produtor agrícola com o setor fornecedor de insumos tecnológicos se dá mediante contratos, em que a idéia de custos de transação está presente e pode ser entendida como aqueles custos existentes no rompimento de uma relação contratual em sua totalidade. Assim sendo, tanto para o capital-estoque quanto para o capital-fluxo, as atividades de P\&D são de grande importância contratual, no intuito de aumentar a produtividade agrícola. A tecnologia gerada precisa ser internalizada em nível da firma para que haja uma adoção bem-sucedida.

De acordo com Foss (1994), tem-se uma argumentação de que o enfoque evolucionário pode ser trabalhado de forma combinada e complementar à teoria dos custos de transação. A importância do investimento no aumento da produtividade agrícola pode ser vista por meio de uma perspectiva institucional. $\mathrm{O}$ mercado institucional possui uma relação na determinação dos investimentos, particularmente com os investimentos na produção de bens públicos. Cabe ao governo conceber e administrar instituições (sistemas legais, regulamentos e políticas de concorrência), incentivar a eficiência na produção privada (agrícola) e investir, quando necessário, na oferta de bens públicos. Nesse sentido, existe uma complexa relação entre as várias instituições (públicas e privadas) ao longo da cadeia produtiva da agricultura.

Formalmente, conforme Vieira Filho (2004), o Modelo Evolucionário de Crescimento Agrícola - MECA, procura definir conceitos novos, os quais possam se adequar à análise da realidade agrícola. ${ }^{9}$ Além disso, com o enfoque proposto de análise, os parâmetros devem se adequar ao mercado agrícola. Como já visto, neste artigo, o capital pode tomar duas formas: capital-estoque $\left(K e_{i t}\right)$ e capital-fluxo $\left(K f_{i t}\right)$, tendo cada um a sua respectiva produtividade.

9 Para um modelo evolucionário setorial industrial que incorpora elementos keynesianos e kalekianos, ver Possas et al. (2001). Por outro lado, para uma visão multissetorial (bens de capital, matérias-primas, consumo básico e supérfluo) e com a incorporação de um sistema financeiro evoluído, ver Cavalcanti Filho (2002). 
Desta forma, apresenta-se o modelo evolucionário de crescimento agrícola geminado, o qual concilia a idéia dos dois tipos de capital em uma mesma função de produção. $^{10}$

De maneira genérica, o MECA pode ser descrito como abaixo. A quantidade produzida, como mostra a equação 1 , é determinada como uma função de produção de proporções fixas entre duas formas de capital estabelecidas anteriormente. ${ }^{11}$ A produção da atividade agrícola $i$ no período $t$ é igual ao mínimo do quociente entre os capitais empregados $\left(K e_{i t}\right.$ ou $\left.K f_{i t}\right)$ e os seus respectivos coeficientes técnicos $\alpha$ e $\beta$ onde $n$ é uma constante de ajuste da proporcionalidade entre os insumos do modelo. Logo:

$$
K e_{i t}=\frac{\alpha \cdot Q_{i t}}{n} \text { e } K f_{i t}=\beta \cdot Q_{i t}
$$

Assim, a produção $Q_{i t}$ se limita ao máximo dado pela combinação mínima entre esses dois fatores. Se

$$
\frac{n \cdot K e_{i t}}{\alpha}<\frac{K f_{i t}}{\beta}
$$

haverá sobra do segundo fator. Se o contrário ocorrer,

$$
\frac{n \cdot K e_{i t}}{\alpha}>\frac{K f_{i t}}{\beta}
$$

haverá excesso do capital-estoque. Desse modo, a função de produção fica definida como:

$$
Q_{i t}=\min \left\{\frac{n \cdot K e_{i t}}{\alpha} ; \frac{K f_{i t}}{\beta}\right\}
$$

A relação inicial entre o capital-fluxo e o capital-estoque é dada por

$$
\frac{K f_{i t}}{K e_{i t}}=z_{i t}
$$

10 É importante ressaltar que o modelo ora apresentado poderá ser interpretado em termos de firmas, atividades ou regiões agrícolas, dependendo do tipo de análise que se pretende realizar ou do tipo de unidade de seleção escolhida. O ponto central é identificar a concorrência schumpeteriana como busca de lucros extraordinários e a concentração de recursos produtivos, seja intrafirmas, setorial ou regional.

11 Para uma explanação acerca da função de produção com proporções fixas de insumos, ver Apêndice A, o qual foi baseado em Ferguson (1972) e acrescido da função dinâmica tratada no MECA. 
Por outro lado, tem-se que

$$
\frac{\frac{K f_{i t}}{\beta}}{\frac{K e_{i t}}{\alpha}}=\frac{K f_{i t}}{\beta} \cdot \frac{\alpha}{K e_{i t}}=n
$$

Assim, fazendo a substituição, chega-se ao resultado que

$$
n \cdot \frac{\beta}{\alpha}=z_{i t}
$$

Então, no estado inicial do sistema $z_{i t}$ é dado, uma vez que $\alpha$ e $\beta$ são inicialmente dados e $n$ é uma constante. Nesse sentido,

$$
\alpha=\frac{1}{A e_{i t}} \quad \text { e } \quad \beta=\frac{1}{A f_{i t}}
$$

onde $A e_{i t}$ é a produtividade do capital-estoque e $A f_{i t}$ é a produtividade do capital-fluxo. $^{12}$

Quando na função de produção

$$
\frac{n \cdot K e_{i t}}{\alpha}<\frac{K f_{i t}}{\beta}
$$

o modelo escolhe o capital-estoque ( $\left.K e_{i t}\right)$, seguindo a estrutura relacionada. Caso ocorra o contrário,

$$
\frac{n \cdot K e_{i t}}{\alpha}>\frac{K f_{i t}}{\beta}
$$

o capital-fluxo será escolhido $\left(K f_{i t}\right)$, sendo que a mesma lógica se aplica. Porém, deve-se ater ao fato de que a produtividade será $A f_{i t}$ e, nesse caso, será distinta também a depreciação do capital, bem como os parâmetros iniciais.

Sendo assim, conforme a equação 2, a produção agrícola total é o somatório da produção individual de cada atividade em questão.

$$
Q_{t}=\left(\sum Q_{i t}\right)
$$

\footnotetext{
12 No disparo inicial do MECA, $\alpha=6,6 ; \beta=4 ; n=0,27$; e $z=0,16$
} 
O market share $\left(S_{i t}\right)$ da atividade é dado pelo quociente da produção individual e da produção total. Assim, tem-se:

$$
S_{i t}=\left(\frac{Q_{i t}}{Q_{t}}\right)
$$

De acordo com a equação 4, o preço do produto agrícola é determinado pela produção agrícola total, dado a função de demanda, $\mathrm{D}(.) .^{13}$

$$
P_{i t}=D\left(Q_{i t}\right)
$$

O lucro por unidade de capital é igual ao preço do produto multiplicado pela produtividade do capital por unidade produzida, menos os custos unitários de produção (c) e gastos por produção de imitação $\left(r_{i m}\right)$ e inovação $\left(r_{i n}-\mathrm{P} \& \mathrm{D}\right)$, conforme indicado pela equação abaixo. Deve-se lembrar que, se $A_{\bullet i t}=A e_{i t}$; então, $K_{\text {•it }}=K e_{i t}$, ou vice-versa.

$$
\pi_{i t}=\left(P_{t} A_{\text {。it }}-c-r_{i m}-r_{i n}\right) \text {; sendo } A_{\text {oit }}=A e_{i t} \text { ou } A f_{i t}
$$

A atividade em pesquisa e desenvolvimento gera novos níveis de produtividade. Este processo pode ser caracterizado por uma variável dummy independente $\left(d_{i m t}\right.$ e $\left.d_{i n t}\right)$ que assume valor zero ou um, dependendo das características da atividade $i$, que pode realizar uma imitação ou inovação no período $t$. O sucesso de cada evento (imitativo ou inovativo) é proporcional aos investimentos em $\mathrm{P} \& \mathrm{D}$ e ocorre com as respectivas probabilidades definidas nas equações 6 e 7 :

$$
\begin{gathered}
\operatorname{Pr}\left(d_{i m t}=1\right)=a_{m} \cdot r_{i m} \cdot K_{\bullet i t} \\
\operatorname{Pr}\left(d_{\text {int }}=1\right)=a_{n} \cdot r_{i n} \cdot K_{\bullet i t} \text { sendo } K_{\bullet i t}=K e_{i t} \text { ou } K f_{i t}
\end{gathered}
$$

Os parâmetros são definidos de forma que cada probabilidade não assuma valores superiores a uma unidade. Quanto $d_{\text {int }}=d_{\text {imt }}=0$ a atividade agrícola fracassa tanto nos esforços de imitação quanto nos de inovação e, nesse caso, $A_{\bullet i(t+1)}=A_{\boldsymbol{\bullet} i t}$. Quando $d_{i m t}=1$, a atividade tem acesso à melhor produtividade tecnológica $\left(\hat{A}_{\text {oit }}\right)$. Assim, a atividade é imitadora, a mesma observa e copia a

\footnotetext{
13 Trabalha-se com uma curva de demanda com elasticidade unitária. Nesse caso, a receita total permanece constante após a variação do preço. Para uma explicação algébrica, ver Binger \& Hoffman (1998) e Ferguson (1972). Ademais, o Apêndice B apresenta o encadeamento matemático.
} 
atividade líder no mercado. Por outro lado, quando $d_{\text {int }}=1$, a atividade é inovadora. Neste caso, tem-se uma distribuição de oportunidades tecnológicas, $F\left(A_{\bullet} ; t ; A_{\bullet i t}\right)$. Esta distribuição é uma função do tempo e é independente da tecnologia dominante das firmas em cada caso. Isto é independente do tempo, mas dependente da acumulação tecnológica. Para uma atividade obter uma imitação e uma inovação em um período específico, os níveis de produtividades dos períodos seguintes são dados por:

$$
A_{\bullet i(t+1)}=\operatorname{Max}\left(A_{\bullet i t} ; \hat{A}_{\bullet t} ; \tilde{A}_{\bullet i t}\right)
$$

Sendo $\hat{A}_{\bullet t}$ o nível mais elevado de produtividade agroindustrial no período $t$, e $\tilde{A}_{\text {sit }}$ o nível oriundo do evento inovativo determinado por uma variável aleatória, tal que: $\log \left[\tilde{A}_{\text {it }}\right]$ tem uma distribuição normal, $N\left[\lambda_{t}, \sigma^{2}\right]$. O efeito de aprendizado é representado por $\lambda_{t}=a+b \cdot t$, crescendo a uma taxa constante ao longo do tempo. É óbvio que uma atividade pode falhar em obter uma imitação, uma inovação, ou ambas, o que levará a permanecer no mesmo nível anterior de produtividade.

A expansão ou contração da atividade é determinada pela taxa dada entre o preço e o custo de produção (P/(c/A)) e o market share. O financiamento dos investimentos é limitado pela margem de lucro empresarial, o qual afeta os gastos em P\&D, que por sua vez afetam os custos de produção. Tem-se a equação 9:

$$
K_{\bullet i(t+1)}=I\left(\frac{P_{t} \cdot A_{\bullet i(t+1)}}{c} ; \frac{Q_{i t}}{Q_{t}} ; \pi_{i t} ; \delta\right) \cdot K_{\bullet i t}+(1-\delta) K_{\bullet i t}
$$

e a restrição financeira para o investimento como função do lucro e do empréstimo bancário dado por:

$$
f(\pi)=\left\{\begin{array}{cccc}
\delta+\pi & \text { para } \pi \leq 0 \\
\delta+2 \pi & \text { para } \pi>0 & \text { e } & \text { banco }=1 \\
\delta+3.5 \pi & \text { para } \pi>0 & \text { e } & \text { banco }=2.5
\end{array}\right.
$$

Cabe observar que, ao discutir capital-estoque e capital-fluxo, a taxa de depreciação é maior no capital-fluxo, chegando à taxa próxima de 1. Quanto 
ao capital-estoque, a taxa de depreciação é menor, haja vista que este tipo de capital se deprecia ao longo do tempo.

Assume-se com a equação 10 que, em outras palavras, a atividade que tem o preço igual ao custo, market share administrável, ausência de gastos em P\&D e, portanto, lucratividade zerada, não fará investimentos. De outra forma, o investimento se dará na mesma proporção da reposição do capital.

$$
\lim _{s \rightarrow 0} I(1, s, 0, \delta)=\delta
$$

Por fim, a equação 11 calcula o Inverso do Índice de Hirschman-Herfindahl $\left(H H I^{2}\right)$, no intuito de obter um outro indicador de concentração de mercado, sendo este indicador associado ao market share das atividades na equação 3 definida anteriormente.

$$
H H I^{2}{ }_{t}=\frac{1}{\sum_{1}^{i}\left(S_{i t}\right)^{2}}
$$

O Índice de Hirschman-Herfindahl é um indicador de concentração de mercado, que varia de 1 (concentração máxima, onde $S_{i t}=1$ ) a $1 /$ n (todas as propriedades com a mesma participação, onde n é o número de firmas no mercado). O seu inverso varia, portanto, de 1 (concentração total) até n (concentração mínima). $\mathrm{O} H H I_{t}^{2}$ está intimamente ligado às variações dinâmicas dos market shares.

Quanto à programação do MECA, faz-se o uso do software Laboratory for Simulation Development (LSD), desenvolvido por Valente (1999). Embora as trajetórias de longo prazo estejam imersas em um mundo não-ergódico, dependentes de decisões empresariais e de aspectos cumulativos da dinâmica do progresso técnico e aprendizado, é possível identificar regularidades, que possam reduzir a incerteza e direcionar as decisóes de longo prazo. Mediante alguns parâmetros iniciais a serem adotados de forma $a d$ hoc, ${ }^{14}$ foi possível obter trajetórias por simulação de resultados específicos de um processo de competição entre firmas agrícolas de uma atividade específica.

\footnotetext{
14 Para tal pesquisa, foi realizado um tipo de educated guess, a fim de determinar as características estruturais do mercado agrícola, no qual se inserem as atividades produtoras de grãos no Brasil.
} 


\section{Mudanças estruturais na agricultura brasileira: uma perspectiva regional}

Vale enfatizar que este artigo visa inserir na análise da economia agrícola o enfoque da teoria evolucionária do crescimento econômico. Dessa forma, seguindo as idéias evolucionárias, pode-se estabelecer uma discussão do processo de crescimento das atividades produtoras de grãos no Brasil, aqui selecionadas apenas as produçõos de arroz, café, feijão, milho, soja, sorgo e trigo por se entender que essas atividades representam características relevantes do mercado agrícola como um todo e no desenvolvimento tecnológico da agricultura brasileira.

Ao estudar a evolução da produção brasileira de grãos, diferenças podem ser vistas ao se comparar às produçôes de milho, soja e sorgo com as de arroz, café, feijāo e trigo, no período de 1990 a 2002. Para entender o enfoque evolucionário das atividades agrícolas, é preciso não só conhecer o comportamento de outras variáveis, ou seja, área colhida, produtividade, preços, insumos tecnológicos, participação de mercado, mas também compreender a relação setorial e regional dentro do crescimento agrícola.

Os resultados da Taxa Geométrica de Crescimento (TGC) $)^{15}$ para a produção, área colhida e rendimento são apresentados na Tabela 1. O aumento (ou redução) da produção pode ser explicado pelo comportamento da taxa de crescimento da produtividade somada à taxa de crescimento da área colhida (TGC da produção = TGC da produtividade + TGC da área colhida). Se houver um aumento da produção, este aumento pode ser explicado pela introdução de novas tecnologias que irão refletir em uma maior produtividade ou pela incorporação de áreas cultivadas. Verifica-se um decréscimo da área colhida na década de 1990 para o conjunto das atividades selecionadas, com exceção das culturas de soja e de sorgo. O comportamento tanto da soja quanto do sorgo, no período, deve-se à incorporação de novas fronteiras agrícolas. Já no que se refere especificamente à soja, o crescimento de sua produtividade dá-se simultaneamente ao aumento da área colhida, devido ao papel das novas tecnologias como fator determinante desse crescimento. Todavia, para o arroz, o feijão e o milho, o aumento da produtividade mais que compensou a redução da área colhida, o que proporcionou crescimento da produção.

\footnotetext{
15 Para uma análise descritiva do cálculo da TGC, ver o modelo de crescimento simples em Gujarati (2000).
} 
TABELA 1

Produção, área colhida, produtividade e taxa geométrica de crescimento por atividades agrícolas selecionadas, Brasil, 1990 a 2002

\begin{tabular}{|c|c|c|c|c|c|c|c|c|c|c|c|c|c|c|c|c|}
\hline & Variáveis* & 1990 & 1991 & 1992 & 1993 & 1994 & 1995 & 1996 & 1997 & 1998 & 1999 & 2000 & 2001 & 2002 & TGC & Pro \\
\hline \multirow{3}{*}{$\begin{array}{l}0 \\
\alpha \\
\alpha \\
\alpha\end{array}$} & Produção & 7,42 & 9,50 & 9,96 & 10,14 & 10,50 & 11,23 & 9,99 & 9,29 & 7,74 & 11,78 & 11,09 & 10,20 & 10,47 & 1,39 & \\
\hline & Área Colhida & 3,94 & 4,13 & 4,69 & 4,42 & 4,42 & 4,38 & 3,92 & 3,57 & 3,07 & 3,84 & 3,66 & 3,14 & 3,15 & $-2,74$ & \\
\hline & Produtividade & $1.880,5$ & $2.300,8$ & $2.125,4$ & $2.294,4$ & $2.378,0$ & $2.565,4$ & $2.550,1$ & $2.601,1$ & $2.523,1$ & $3.068,4$ & $3.033,9$ & $3.245,3$ & $3.326,3$ & 4,25 & \\
\hline
\end{tabular}

\begin{tabular}{|c|c|c|c|c|c|c|c|c|c|c|c|c|c|c|}
\hline Produção & 2,93 & 3,05 & 2,59 & 2,56 & 2,61 & 1,86 & 2,69 & 2,34 & 3,45 & 3,27 & 3,78 & 1,92 & 2,49 & $-0,13$ \\
\hline Área Colhida & 2,91 & 2,77 & 2,50 & 2,26 & 2,10 & 1,87 & 1,99 & 2,05 & 2,08 & 2,21 & 2,27 & 2,35 & 2,36 & $-1,32$ \\
\hline Produtividade & $1.007,0$ & $1.102,3$ & $1.035,5$ & $1.132,1$ & $1.246,7$ & 994,8 & $1.349,6$ & $1.141,7$ & $1.657,5$ & $1.480,2$ & $1.664,3$ & 814,9 & $1.054,7$ & 1,21 \\
\hline
\end{tabular}

\begin{tabular}{|c|c|c|c|c|c|c|c|c|c|c|c|c|c|c|}
\hline Produção & 2,23 & 2,75 & 2,80 & 2,48 & 3,37 & 2,95 & 2,82 & 2,99 & 2,20 & 2,82 & 3,04 & 2,44 & 3,05 & 0,63 \\
\hline Área Colhida & 4,68 & 5,44 & 5,15 & 3,89 & 5,47 & 5,00 & 4,94 & 4,83 & 3,32 & 4,15 & 4,33 & 3,45 & 4,15 & $-2,46$ \\
\hline Produtividade & 477,2 & 505,1 & 543,5 & 638,0 & 615,9 & 589,7 & 570,6 & 619,4 & 661,9 & 679,2 & 701,3 & 706,4 & 735,4 & 3,16 \\
\hline
\end{tabular}

\begin{tabular}{|c|c|c|c|c|c|c|c|c|c|c|c|c|c|c|}
\hline Produção & 21,34 & 23,74 & 30,52 & 30,00 & 32,49 & 36,27 & 32,19 & 34,60 & 29,49 & 32,04 & 31,88 & 41,44 & 35,50 & 3,33 \\
\hline Área Colhida & 11,39 & 13,11 & 13,39 & 11,87 & 13,75 & 13,96 & 13,42 & 13,55 & 10,61 & 11,61 & 11,61 & 12,35 & 11,79 & $-0,70$ \\
\hline ade & $1.873,6$ & 810,8 & $.279,5$ & $2.528,2$ & $2.363,1$ & $2.598,5$ & $2.399,1$ & $2.552,6$ & $2.781,1$ & $2.759,8$ & $2.744,7$ & $3.354,1$ & $3.010,7$ & 4,06 \\
\hline
\end{tabular}

\begin{tabular}{|c|c|c|c|c|c|c|c|c|c|c|c|c|c|c|}
\hline Produção & 19,89 & 14,94 & 19,18 & 22,56 & 24,91 & 25,65 & 23,56 & 26,43 & 31,37 & 30,90 & 32,73 & 37,68 & 42,03 & 7,22 \\
\hline Área Colhida & 11,48 & 9,62 & 9,44 & 10,63 & 11,51 & 11,66 & 10,74 & 11,50 & 13,26 & 13,01 & 13,64 & 13,93 & 16,35 & 3,53 \\
\hline ade & $1.732,2$ & 553,1 & 33,2 & $.122,6$ & 163,6 & $2.200,4$ & $2.194,7$ & $2.297,5$ & $2.366,2$ & $2.375,5$ & $2.399,9$ & $2.705,0$ & 571,2 & 3,56 \\
\hline
\end{tabular}

\begin{tabular}{|c|c|c|c|c|c|c|c|c|c|c|c|c|c|c|}
\hline & 0,23 & 0,25 & 0,29 & 0,25 & 0,29 & 0,24 & 0,34 & 0,47 & 0,60 & 0,57 & 0,78 & 0,90 & 0,77 & 13,02 \\
\hline Área Colhida & 0,13 & 0,17 & 0,16 & 0,13 & 0,15 & 0,14 & 0,19 & 0,27 & 0,33 & 0,36 & 0,52 & 0,49 & 0,42 & 12,99 \\
\hline Produtividade & $1.708,3$ & $1.480,7$ & $1.794,0$ & $2.011,6$ & $1.909,9$ & $1.746,6$ & $1.776,4$ & $1.782,6$ & $1.793,6$ & $1.588,8$ & $1.487,9$ & $1.861,0$ & $1.846,1$ & 0,03 \\
\hline
\end{tabular}

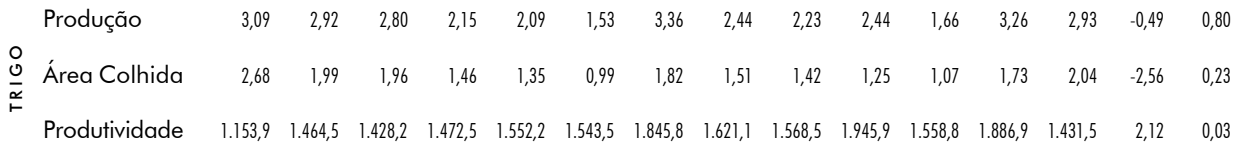

Fonte: elaboração a partir de dados do IBGE-LSPA e PAM (vários anos).

Obs $\left({ }^{*}\right)$ : produção (milhões de toneladas); área colhida (milhões de hectares); e produtividade (quilogramas por hectares).

444 Revista Brasileira de Inovação 
Ao comparar o comportamento dos rendimentos físicos médios dessas atividades, percebe-se que arroz, milho e soja obtiveram rendimentos crescentes. No caso específico do arroz e do milho, a elevação do rendimento médio, de 1990 a 2002, deve-se à redução da área colhida, o que possibilitou a exclusão das áreas marginais de plantio. As atividades produtoras de feijão e trigo apresentaram um moderado aumento dos seus rendimentos, embora a área colhida tenha sido reduzida. Por fim, constata-se uma certa estabilidade na produtividade do sorgo, enquanto que há um aumento no rendimento do café até o ano 2000, porém com redução a partir dos dois últimos anos. Quando o foco se atém à produtividade de um modo geral, o conjunto das atividades produtoras de grãos apresenta taxas positivas, o que é um indício da adoção de novos insumos ou técnicas de produção (mudança tecnológica).

Conforme o AGRIANUAL (2002), os preços desses produtos não apresentaram tendências crescentes no longo prazo. O resultado final indica uma tendência declinante para todos os produtos no período de 1991 a 2001. No geral, de acordo com este comportamento dos preços agrícolas, surge a questão de como a tecnologia ${ }^{16}$ influencia o crescimento setorial dessas atividades, haja visto que a queda do nível dos preços acontece com aumento simultâneo da oferta de grãos.

Em termos mundiais, Tabela 2, o Brasil possui participação média expressiva nas produçôes de café, soja e feijão, respectivamente 43, 19 e 17 pontos percentuais. Com exceção do café e do trigo, que perderam participações nos totais mundiais, as demais atividades produtoras de grãos elevaram o seu respectivo market share. A evolução da produção de grãos no Brasil é vista, no período considerado, como um processo ininterrupto de introdução e difusão de inovações no "espaço econômico", no qual as empresas competem por buscas de lucros extraordinários.

Em termos regionais, as áreas da fronteira agrícola são entendidas como aquelas regiôes relativamente desocupadas e economicamente pouco exploradas,

\footnotetext{
16 Existem várias formas de mensurar a variável tecnológica em uma economia por meio de uma proxy. Algumas dessas formas podem utilizar dados de patentes tecnológicas, publicações de artigos acadêmicos indexados em revistas internacionais e até mesmo composição acadêmica em termos de disciplina. Para o Brasil, conforme Albuquerque (2003), há uma especialização científica revelada em termos das disciplinas de agricultura e de agronomia, o que comprova a relevância da ciência e pesquisa para o setor agrícola no País. Em termos de patentes, embora os dados da United States Patent and Trademark Office - USPTO, não tenham apresentado liderança nos indicadores na década de 1990, sabe-se que a maior parte das patentes agrícolas relevantes ao mercado brasileiro é registrada no Instituto Nacional de Propriedade Intelectual - INPI. Sendo assim, os dados da USPTO são subestimados no tocante à realidade brasileira.
} 
TABELA 2

Participação da produção brasileira no mundo por atividade agrícola selecionada de 1990 a 2002 (\%)

\begin{tabular}{lcccccccc}
\hline Anos & Arroz & Café & Feiião & Milho & Soja & Sorgo & Trigo & Total \\
\hline 1990 & 1,4 & 48,3 & 13,1 & 4,4 & 18,3 & 0,4 & 0,5 & 3,2 \\
1991 & 1,8 & 50,0 & 16,8 & 4,8 & 14,5 & 0,5 & 0,5 & 3,3 \\
1992 & 1,9 & 42,5 & 18,2 & 5,7 & 16,8 & 0,4 & 0,5 & 3,7 \\
1993 & 1,9 & 46,0 & 15,9 & 6,3 & 19,6 & 0,4 & 0,4 & 4,0 \\
1994 & 1,9 & 45,4 & 20,0 & 5,7 & 18,3 & 0,5 & 0,4 & 4,1 \\
1995 & 2,1 & 33,7 & 17,4 & 7,0 & 20,2 & 0,4 & 0,3 & 4,4 \\
1996 & 1,8 & 43,3 & 17,1 & 5,5 & 18,1 & 0,5 & 0,6 & 3,8 \\
1997 & 1,6 & 39,5 & 18,9 & 5,9 & 18,3 & 0,8 & 0,4 & 3,9 \\
1998 & 1,3 & 52,3 & 13,9 & 4,8 & 19,6 & 1,0 & 0,4 & 3,8 \\
1999 & 1,9 & 48,4 & 16,7 & 5,3 & 19,6 & 1,0 & 0,4 & 4,1 \\
2000 & 1,8 & 51,0 & 18,2 & 5,4 & 20,3 & 1,4 & 0,3 & 4,2 \\
2001 & 1,7 & 26,3 & 15,0 & 6,7 & 21,3 & 1,5 & 0,6 & 4,7 \\
2002 & 1,8 & 33,9 & 16,6 & 5,9 & 23,4 & 1,4 & 0,5 & 4,8 \\
Média & 1,8 & 43,1 & 16,8 & 5,6 & 19,1 & 0,8 & 0,4 & 4,0 \\
\hline
\end{tabular}

Fonte: elaboração a partir de dados da FAO e do IBGE-LSPA e PAM (vários anos).

mas com amplo potencial de ocupação produtiva. Essas áreas concentram-se no Centro-Oeste, no oeste da Bahia e no sul do Maranhão. Ao contrário do que ocorreu no passado, as ocupações mais recentes associam mudanças nos modos de produzir nessa nova fronteira. Assim, há a passagem de um padrão extensivo para um vetor tecnoindustrial, que segue essa orientação (Sicsú \& Lima, 2000:136): “(...) o capital financeiro e a inovação tecnológica são fundamentais para viabilização econômica dessas áreas." Por outro lado, algumas regiōes demonstram fragilidades infra-estruturais, necessitando de um intervencionismo dos agentes públicos e privados para garantir condiçôes de competitividade.

Nesse sentido, é importante ressaltar o papel das iniciativas governamentais no processo de difusão tecnológica. A pesquisa agrícola na área da produção tem sido conduzida por instituições públicas, enquanto que na produção de 
insumos a pesquisa é realizada quase que exclusivamente pelo setor privado. No âmbito federal, destaca-se o papel da Empresa Brasileira de Pesquisa Agropecuária - EMBRAPA ${ }^{17}$ nas soluções para o desenvolvimento sustentável do agronegócio brasileiro por meio da geração, adaptação e transferência de conhecimentos e tecnologias, representados pelas novas cultivares, que foram em muitos casos catalisados pela indústria privada produtora de insumos para a agricultura. A atuação da EMBRAPA no Brasil proporcionou, por exemplo, que o Centro-Oeste se tornasse uma das maiores fronteiras agrícolas do mundo.

A crescente participação do Centro-Oeste na produção brasileira de grãos dá-se de forma diferenciada (Gráfico 1). Mediante a evolução geográfica da produção, pode-se identificar que em 1990 a produção do Centro-Oeste ficava em torno de 19\%, enquanto em 2002 esta parcela passou para mais de 31\%, o que comprova a potencialidade da região. Por outro lado, as regiōes Sudeste e Sul vêm perdendo participação relativa ao longo do período. Porém, a Região Sul continua sendo a principal produtora agrícola brasileira. O Nordeste, por sua vez, apresentou um ligeiro aumento percentual (de 4,3 para 8,9) na sua participação no período de 1990 a 1996. Entretanto, em 2002, essa participação reduz-se para 6,5 pontos percentuais. Quanto à Região Norte, as suas participações não merecem destaque no contexto nacional, ficando abaixo de 3,2\% em todo o período estudado.

Para melhor entender os padrões regionais do crescimento econômico do Brasil e suas regiôes, utiliza-se o cálculo do Quociente Locacional (QL), indicador que busca explicar o grau de concentração e de dispersão das atividades produtivas agrícolas no espaço econômico. ${ }^{18} \mathrm{O}$ QL compara a participação

17 Criada em 1973, tal organização contribuiu para promover as transformações tecnológicas da Revolução Verde no Brasil, transformando o País em uma das maiores áreas de plantio direto do mundo. Não se pode pensar que o desenvolvimento tecnológico proporcionado pela EMBRAPA seja um processo separado da dinâmica do crescimento agrícola. No que diz respeito ao modelo de simulação, isto não quer dizer que o desenvolvimento tecnológico seja uma variável exógena à determinação do crescimento agrícola. Quando a unidade de seleção for definida como sendo a cadeia produtiva regional, sob uma perspectiva institucional mediante contratos, há uma relação contratual na geração, adaptação e difusão tecnológica entre os vários agentes econômicos (públicos ou privados) ao longo da cadeia produtiva. Portanto, a seleção tecnológica continua sendo parte de um processo endógeno do crescimento agrícola.

18 Deve-se ressaltar que, embora haja limitações no escopo analítico desse indicador, a sua utilização se justifica em trabalhos de natureza exploratória e em associação com outras técnicas de trabalho. As limitações podem ser técnicas ou conceituais. As limitações técnicas comuns a quase todos os métodos de análise regional relacionam-se com problemas de agregação das variáveis em níveis regionais e setoriais. Além disso, os estudos são feitos por análises de estática comparativa, proporcionando perda das interações dinâmicas. Os resultados dos indicadores são sensíveis ao tamanho da região e ao tipo de agregação setorial e, nesse sentido, os padrões encontrados por essas medidas estão condicionados aos processos classificatórios iniciais, o que pode levar a erros de conceituação ou generalização de resultados que não expressam a realidade da região ou do setor. Para uma discussão das limitações dos indicadores de localização, ver Isard (1960, caps. 5 e 7). 
GRÁFICO 1

Participação da produção de grãos (arroz, café, feijão, milho, soja, sorgo e trigo) por regiões no total do Brasil entre os anos de 1990, 1996 e 2002

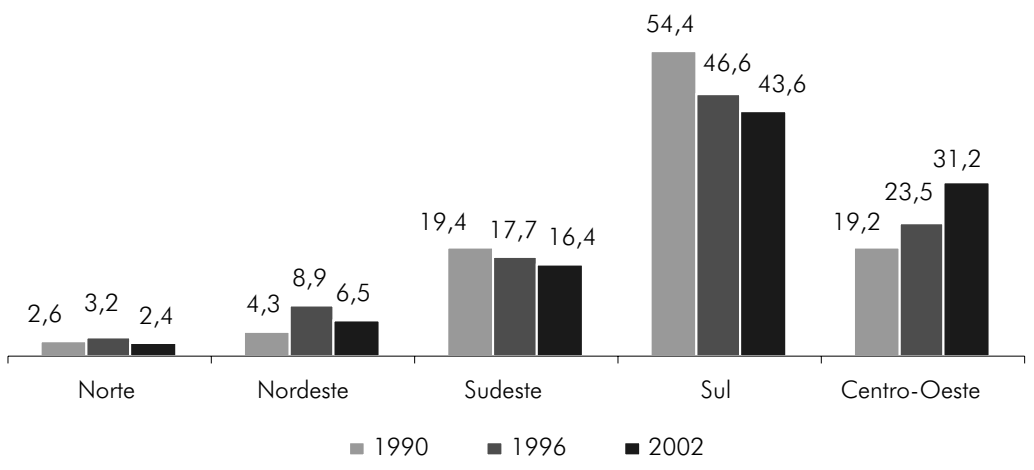

Fonte: elaboração a partir de dados do IBGE-LSPA e PAM (vários anos).

percentual de uma região em uma atividade específica com a participação percentual da mesma região no total produzido da economia nacional. ${ }^{19}$ Valores superiores a 1, há indício de que a região é relativamente mais importante, no contexto nacional, em termos da atividade, do que em termos gerais de todos as atividades. Caso contrário, valores inferiores a 1, a região é relativamente menos importante em comparação à produção nacional.

Conforme resultados da Tabela 3, nota-se que o Brasil apresenta vantagem produtiva nas produções de café, feijão, milho e soja. Entretanto, quanto às produções de arroz, sorgo e trigo, os indicadores foram desfavoráveis. Em termos regionais, quanto à produção de café, o Sudeste destaca-se no conjunto das grandes regiōes brasileiras, por apresentar vantagem produtiva para todos os estados da região. Ainda em relação ao café, tanto Rondônia como Bahia obtiveram estatísticas superiores a uma unidade.

No que se refere à produção de feijão, a região dinâmica vai do Norte e Nordeste ao Sudeste, mesmo que para as duas primeiras regióes alguns estados mostraram desvantagem produtiva. Ao analisar a produção de milho, observase uma descontinuidade produtiva em termos territoriais, ou seja, vários estados

\footnotetext{
19 Desta forma, o QL para uma região j em um produto ou grupo de produtos i pode ser definido da seguinte forma: $\mathrm{QL}_{\mathrm{ij}}=\left(\mathrm{X}_{\mathrm{ij}} / \mathrm{X}_{\mathrm{iz}}\right) /\left(\mathrm{X}_{\mathrm{j}} / \mathrm{X}_{\mathrm{z}}\right)$; onde: $\mathrm{X}_{\mathrm{ij}}$ é a produção $\mathrm{i}$ da região $\mathrm{j}, \mathrm{X}_{\mathrm{iz}}$ é a produção $\mathrm{i}$ da zona de referência, $\mathrm{X}_{\mathrm{j}}$ é a produção total de grãos da região j e $\mathrm{X}_{\mathrm{z}}$ é a produção total de grãos da zona de referência z. Para outros indicadores de concentração e especialização, ver Haddad (1989).
} 
TABELA 3

Quociente Locacional Médio por regiões e por produtos selecionados e como zona de referência à produção total, Brasil, 1990 a 2002

\begin{tabular}{|c|c|c|c|c|c|c|c|c|}
\hline & Estados & Arroz & Café & Feijão & Milho & Soja & Sorgo & Trigo \\
\hline \multirow{7}{*}{$\begin{array}{l}\text { w } \\
\stackrel{\alpha}{\circ} \\
\mathrm{z}\end{array}$} & Rondônia & 2,0 & 7,0 & 2,8 & 0,9 & 0,0 & 0,0 & 0,0 \\
\hline & Acre & 3,1 & 0,1 & 2,5 & 1,3 & 0,0 & 0,0 & 0,0 \\
\hline & Amazonas & 3,5 & 0,0 & 3,2 & 1,1 & 0,0 & 0,0 & 0,0 \\
\hline & Roraima & 6,0 & 0,0 & 0,3 & 0,5 & 0,0 & 0,0 & 0,0 \\
\hline & Pará & 3,3 & 0,0 & 1,7 & 1,3 & 0,0 & 0,0 & 0,0 \\
\hline & Amapá & 4,0 & 0,0 & 2,4 & 1,0 & 0,0 & 0,0 & 0,0 \\
\hline & Tocantins & 5,1 & 0,0 & 0,2 & 0,5 & 0,3 & 0,0 & 0,0 \\
\hline \multirow{9}{*}{$\begin{array}{l}\text { ․ } \\
5 \\
山 \\
\alpha \\
\alpha \\
0 \\
z\end{array}$} & Maranhão & 4,3 & 0,0 & 0,8 & 0,6 & 0,5 & 0,0 & 0,0 \\
\hline & Piauí & 3,4 & 0,0 & 3,0 & 0,9 & 0,2 & 0,0 & 0,0 \\
\hline & Ceará & 2,0 & 0,3 & 6,7 & 1,2 & 0,0 & 0,5 & 0,0 \\
\hline & Rio Grande do Norte & 0,5 & 0,0 & 12,6 & 1,1 & 0,0 & 5,0 & 0,0 \\
\hline & Paraíba & 0,8 & 0,0 & 11,8 & 1,2 & 0,0 & 0,0 & 0,0 \\
\hline & Pernambuco & 1,2 & 0,7 & 11,6 & 1,0 & 0,0 & 0,3 & 0,0 \\
\hline & Alagoas & 2,3 & 0,0 & 11,0 & 0,7 & 0,0 & 0,0 & 0,0 \\
\hline & Sergipe & 2,2 & 0,0 & 6,6 & 1,2 & 0,0 & 0,0 & 0,0 \\
\hline & Bahia & 0,3 & 1,4 & 4,6 & 0,8 & 1,2 & 2,3 & 0,0 \\
\hline \multirow{4}{*}{ 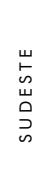 } & Minas Gerais & 0,5 & 5,0 & 1,4 & 1,3 & 0,5 & 0,5 & 0,1 \\
\hline & Espírito Santo & 0,5 & 19,6 & 1,4 & 0,5 & 0,0 & 0,0 & 0,0 \\
\hline & Rio de Janeiro & 2,5 & 4,6 & 2,5 & 1,1 & 0,0 & 0,0 & 0,0 \\
\hline & São Paulo & 0,3 & 1,8 & 1,3 & 1,5 & 0,6 & 2,7 & 0,3 \\
\hline \multirow{3}{*}{ 峁 } & Paraná & 0,1 & 0,3 & 0,8 & 1,2 & 1,1 & 0,0 & 2,7 \\
\hline & Santa Catarina & 1,2 & 0,0 & 1,5 & 1,6 & 0,3 & 0,0 & 0,5 \\
\hline & Rio Grande do Sul & 2,3 & 0,0 & 0,3 & 0,7 & 1,0 & 1,0 & 1,7 \\
\hline \multirow{5}{*}{ 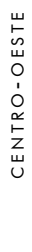 } & Mato Grosso do Sul & 0,4 & 0,0 & 0,2 & 0,8 & 1,7 & 1,0 & 0,6 \\
\hline & Mato Grosso & 0,8 & 0,1 & 0,1 & 0,4 & 2,1 & 1,5 & 0,0 \\
\hline & Goiás & 0,4 & 0,0 & 0,7 & 1,2 & 1,2 & 2,6 & 0,1 \\
\hline & Distrito Federal & 0,1 & 0,1 & 2,2 & 1,2 & 1,3 & 0,0 & 0,0 \\
\hline & BRASIL & 0,4 & 11,1 & 4,2 & 1,4 & 4,8 & 0,2 & 0,1 \\
\hline
\end{tabular}

Fonte: elaboração a partir de dados do IBGE-LSPA e PAM e FAO (vários anos).

Obs $\left(^{*}\right)$ : para o cálculo nacional, a zona de referência foi definida como sendo a produção mundial. 
brasileiros possuem vantagem produtiva, mas não necessariamente existe uma interligação no espaço geográfico. Quanto aos resultados obtidos pela produção de soja, verifica-se vantagem produtiva nos estados da Bahia, Paraná e em toda região do Centro-Oeste, sendo esta a grande fronteira agrícola em expansão.

No outro extremo, ao explicar os resultados das produções de arroz, sorgo e trigo, nota-se uma menor dispersão das regiōes relativamente mais importantes. Quanto à produção de arroz, o Norte e parte do Nordeste apresentaram vantagem produtiva em comparação às demais regiōes. Destacam-se, isoladamente, os estados do Rio de Janeiro, de Santa Catarina e do Rio Grande do Sul. No que se refere ao sorgo, os indicadores foram favoráveis para o Centro-Oeste, bem como para São Paulo, Rio Grande do Norte, Bahia e Rio Grande do Sul.

Por fim, quanto ao trigo, percebe-se que esta atividade perde relativa importância ao longo do tempo, haja vista que a produção deixa de ser um atrativo regional face à competição externa. Ao analisar a produção de trigo, os indicadores foram inferiores à unidade, com exceção apenas do Rio Grande do Sul e do Paraná. Cabe salientar que o trigo apresentou desvantagem produtiva no âmbito nacional. Após a abertura comercial e o acordo do MERCOSUL, a competição externa afetou seriamente a produção de trigo.

No intuito de caracterizar a evolução da oferta de capital, procede-se à análise de dados regionais da produção de fertilizantes, defensivos e máquinas agrícolas. Conforme a Tabela 4, tem-se o número de estabelecimentos produtivos e suas participações por regióes brasileiras entre os anos de $1996 \mathrm{e}$ 2002. Os números demonstram que o Sudeste concentra mais da metade dos estabelecimentos produtivos totais, sejam nos fertilizantes ou nos defensivos agrícolas. Todavia, há uma queda da participação do Sudeste, de 1996 para 2002, no grupo de fertilizantes e intermediários. Em compensação, para o Sul e para o Centro-Oeste, verificam-se aumentos nas participações de fertilizantes no período considerado. No que se refere às máquinas agrícolas, o Sul e o Sudeste concentram o número de estabelecimentos como um todo. Já as regiōes Norte e Nordeste possuem baixa representatividade em qualquer grupo de fabricação desses produtos, seja capital-fluxo ou capital-estoque.

Pela Tabela 5, têm-se estatísticas do valor agregado, em milhões de reais, para cada grupo de produtos. Os segmentos que mais agregaram valor foram os 
TABELA 4

Número e participação de unidades locais por grupos de fabricação de produtos intermediários (fertilizantes, defensivos e máquinas agrícolas) por regiões brasileiras, 1996 e 2002

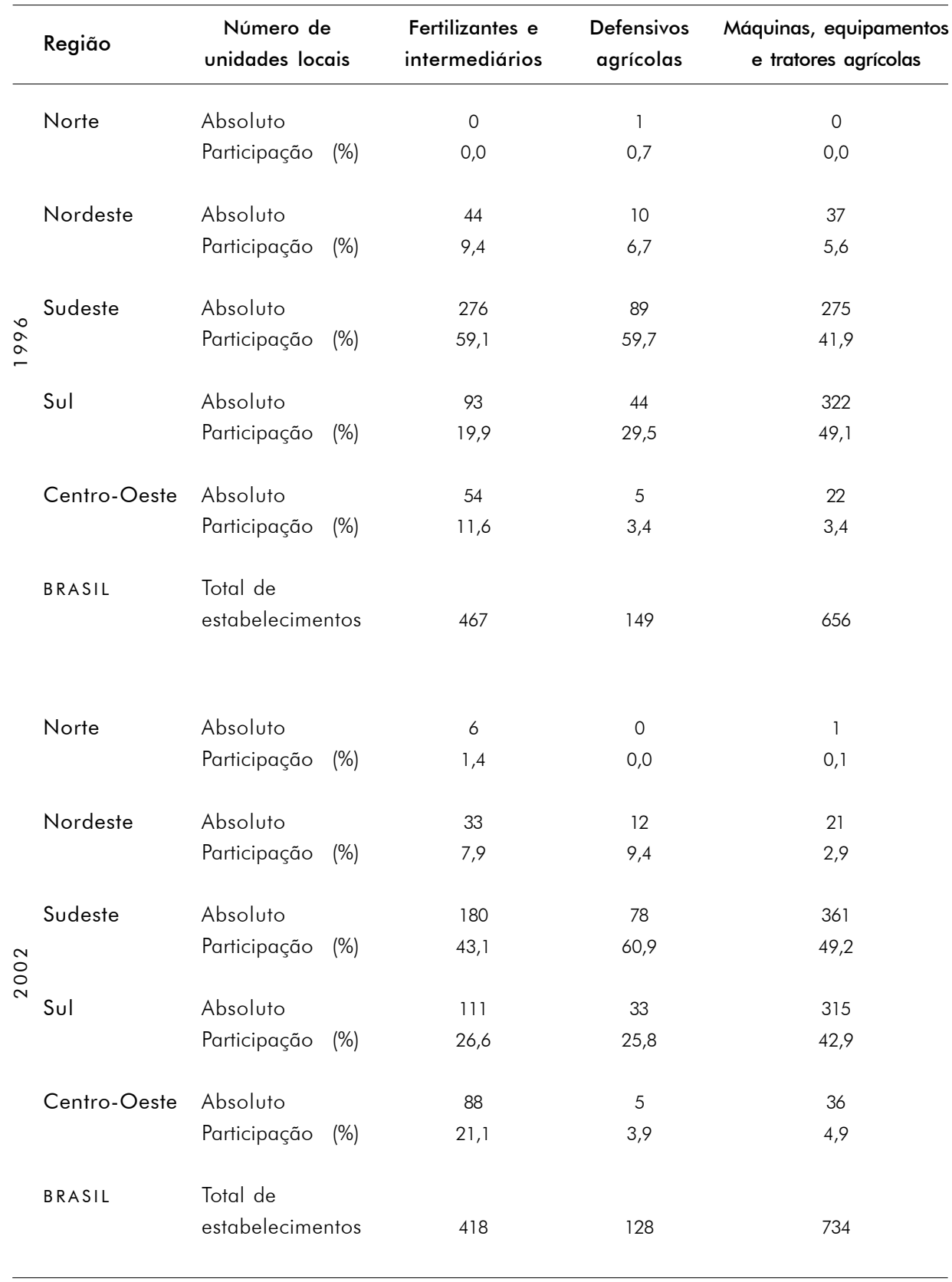

Fonte: elaboração a partir de dados do IBGE-PIA (1996-2002). 
TABELA 5

Valor da transformação industrial e participação por grupos de fabricação de produtos intermediários (fertilizantes, defensivos e máquinas agrícolas) por regiões brasileiras, 1996 e 2002 (milhões de reais)

\begin{tabular}{|c|c|c|c|c|c|}
\hline & Região & $\begin{array}{l}\text { Número de } \\
\text { unidades locais }\end{array}$ & $\begin{array}{l}\text { Fertilizantes e } \\
\text { intermediários }\end{array}$ & $\begin{array}{l}\text { Defensivos } \\
\text { agrícolas }\end{array}$ & $\begin{array}{c}\text { Máquinas, equipamentos } \\
\text { e tratores agrícolas }\end{array}$ \\
\hline & \multirow[t]{2}{*}{ Norte } & Absoluto & 0,0 & 0,0 & 0,0 \\
\hline & & Participação (\%) & 0,0 & 0,0 & 0,0 \\
\hline & \multirow[t]{2}{*}{ Nordeste } & Absoluto & 418,2 & 103,3 & 8,0 \\
\hline & & Participação (\%) & 15,1 & 4,4 & 0,5 \\
\hline & \multirow[t]{2}{*}{ Sudeste } & Absoluto & $1.368,1$ & $1.790,1$ & 782,6 \\
\hline 2 & & Participação (\%) & 49,4 & 76,6 & 53,5 \\
\hline & \multirow[t]{2}{*}{ Sul } & Absoluto & 713,7 & 435,1 & 669,4 \\
\hline & & Participação (\%) & 25,8 & 18,6 & 45,8 \\
\hline & \multirow[t]{2}{*}{ Centro-Oeste } & Absoluto & 66,4 & 0,0 & 2,3 \\
\hline & & Participação (\%) & 2,4 & 0,0 & 0,2 \\
\hline & \multirow[t]{2}{*}{ BRASIL } & Total de & & & \\
\hline & & estabelecimentos & $2.767,6$ & $2.336,8$ & $1.462,2$ \\
\hline & \multirow[t]{2}{*}{ Norte } & Absoluto & 4,5 & 0,0 & 0,0 \\
\hline & & Participação (\%) & 0,2 & 0,0 & 0,0 \\
\hline & \multirow[t]{2}{*}{ Nordeste } & Absoluto & 185,6 & 0,8 & 19,0 \\
\hline & & Participação (\%) & 6,8 & 0,1 & 0,8 \\
\hline & \multirow[t]{2}{*}{ Sudeste } & Absoluto & $1.537,3$ & 914,1 & $1.188,3$ \\
\hline 웅 & & Participação (\%) & 56,6 & 56,3 & 51,2 \\
\hline & \multirow[t]{2}{*}{ Sul } & Absoluto & 680,8 & 411,7 & $1.106,6$ \\
\hline & & Participação (\%) & 25,1 & 25,3 & 47,7 \\
\hline & \multirow[t]{2}{*}{ Centro-Oeste } & Absoluto & 147,4 & 0,0 & 7,1 \\
\hline & & Participação (\%) & 5,4 & 0,0 & 0,3 \\
\hline & \multirow[t]{2}{*}{ BRASIL } & Total de & & & \\
\hline & & estabelecimentos & $2.713,9$ & $1.625,1$ & $2.321,2$ \\
\hline
\end{tabular}

Fonte: elaboração a partir de dados do IBGE-PIA (1996-2002).

Obs.: o valor da transformação industrial foi corrigido para preços de dezembro de 2002 pelo IPA-OG de Fertilizantes, de Química e de Máquinas Agrícolas da FGV. 
de fertilizantes e os de máquinas agrícolas, nesta ordem. Em termos regionais, a principal região produtora de fertilizantes, defensivos e máquinas agrícolas foi a Sudeste, seguida pela região Sul. ${ }^{20}$ Assim sendo, nota-se uma relação entre o número de estabelecimentos e o valor da transformação regional. Porém, quanto ao Centro-Oeste, embora essa região apresente um percentual elevado de estabelecimentos, a sua participação em termos de valor da transformação industrial de fertilizantes é bem menor. É importante observar que a região mais dinâmica continua sendo a Sul, seguida pela Sudeste. Em uma menor escala, destaca-se a importância do Centro-Oeste por seu elevado potencial agrícola.

Segundo Vieira Filho (2004), ao final do período, há uma aproximação do valor da transformação industrial ${ }^{21}$ entre os segmentos analisados. Observa-se que, após a desvalorização cambial em 1999, os custos industriais do setor químico são elevados, posto que este setor é um grande importador de matériasprimas e insumos produtivos. Com o aumento dos custos produtivos, tem-se uma contração do valor da transformação industrial do setor fabricante de defensivos agrícolas e uma leve redução do valor agregado do setor fabricante de fertilizantes, dado que no geral o valor bruto da produção industrial do setor químico cresceu pouco no mesmo período. Ao contrário, o setor de máquinas e equipamentos foi beneficiado com a desvalorização, que encareceu a importação do produto final e induziu a substituição das peças importadas por produção doméstica, elevando, assim, o valor da transformação industrial desse segmento.

A competitividade do setor produtor de grãos depende de como a inovação tecnológica é tratada no segmento produtor de insumos para a agricultura. De acordo com a Pesquisa Industrial de Inovação Tecnológica (PINTEC) ${ }^{22}$ seguindo a recomendação internacional, a inovação tecnológica é definida pela implementação de produtos (bens e serviços) ou processos tecnologicamente

${ }^{20}$ As estatísticas desagregadas por regiões, em até quatro dígitos da Classificação Nacional de Atividades Econômicas CNAE, e que permitam identificar o estabelecimento informante, são omitidas, com a finalidade de manter o sigilo das informações pesquisadas. Nesse sentido, os informes apresentados para o valor da transformação industrial podem estar subestimados, embora representem um percentual acima de $90 \%$ de toda a transformação regional para os grupos de fabricação de produtos, especificamente no tocante aos fertilizantes e defensivos agrícolas.

${ }^{21}$ O Valor da Transformação Industrial - VTI, é uma proxy do Valor Agregado. Conforme metodologia estatística estabelecida pelo IBGE, o seu cálculo é obtido através da diferença entre o Valor Bruto da Produção Industrial - VBPI, e o Custo das Operações Industriais - COI. O VBPI é a soma da receita líquida industrial à variação dos estoques de produtos finais e em elaboração, e o COI é a soma dos custos diretos da produção industrial (matéria-prima, compra de energia elétrica, consumo de combustível, peças e acessórios, serviços industriais e manutenção e reparação de máquinas e equipamentos ligados à produção prestados por terceiros).

22 Para os valores estimados da PINTEC e apresentados no presente trabalho, não foram constatados problemas com os respectivos coeficientes de variação. 
TABELA 6

Empresas que implementaram inovações (produto e processo), com indicação de depósito de patentes e de patentes em vigor, segundo atividades industriais selecionadas, Brasil, 1998 a 2000

\begin{tabular}{|c|c|c|c|c|c|c|c|c|}
\hline & $\begin{array}{l}\text { Fertilizantes e } \\
\text { intermediários }\end{array}$ & s (\%) & $\begin{array}{r}\text { Defensi } \\
\text { agrícol }\end{array}$ & os & $\begin{array}{l}\text { Máquinas } \\
\text { e tratores }\end{array}$ & $(\%)$ & $\begin{array}{c}\text { Brasil } \\
\text { (todos os setc }\end{array}$ & s) (\%) \\
\hline \multicolumn{9}{|l|}{ Empresas que } \\
\hline implementaram inovações & 123 & 40,7 & 33 & 73,3 & 235 & 71,2 & 22.698 & 31,5 \\
\hline Produto & 113 & 37,4 & 31 & 68,9 & 216 & 65,5 & 12.658 & 17,6 \\
\hline Processo & 82 & 27,2 & 15 & 33,3 & 103 & 31,2 & 18.160 & 25,2 \\
\hline Produto e Processo & 72 & 23,8 & 13 & 28,9 & 84 & 25,5 & 8.120 & 11,3 \\
\hline Com depósito de patente & 14 & 4,6 & 3 & 6,7 & 99 & 30,0 & 1.827 & 2,5 \\
\hline Com patente em vigor & 24 & 7,9 & 8 & 17,8 & 73 & 22,1 & 1.930 & 2,7 \\
\hline Empresas (População) & 302 & 100,0 & 45 & 100,0 & 330 & 100,0 & 72.005 & 100,0 \\
\hline
\end{tabular}

Fonte: elaboração a partir de dados do IBGE-PINTEC (2000).

novos ou substancialmente aprimorados. A inovação acontece quando o produto é introduzido no mercado ou quando o processo passa a ser implementado no sistema produtivo.

Para uma dimensão do comportamento inovativo dos segmentos produtores de insumos para a agricultura, a Tabela 6 contém dados referentes às empresas que implementaram inovações no sentido amplo. Comparativamente, os segmentos produtores de insumos (fertilizantes, defensivos, máquinas e tratores agrícolas) implementaram mais inovaçôes em produto do que em processo, o que mostra o direcionamento em criar novas tecnologias para a produção agrícola. Normalmente, o percentual das empresas que implementaram inovaçôes foi maior do que a média nacional. No caso específico de defensivos e máquinas agrícolas, mais de 70\% das empresas buscaram inovações tecnológicas. Quanto ao depósito de patentes, todos os segmentos produtores de insumos tiveram percentuais superiores à média da economia, o que identifica a relevância do segmento de insumos para o setor de produção agrícola. 
TABELA 7

Principal responsável pelo desenvolvimento de produto e/ou processo nas empresas que implementaram inovações, segundo atividades industriais selecionadas, Brasil, 1998 a 2000

\begin{tabular}{|c|c|c|c|c|c|}
\hline & & $\begin{array}{l}\text { Fertilizantes e } \\
\text { intermediários }\end{array}$ & $\begin{array}{l}\text { Defensivos } \\
\text { agrícolas }\end{array}$ & $\begin{array}{l}\text { Máquinas } \\
\text { e tratores }\end{array}$ & $\begin{array}{c}\text { Brasil } \\
\text { (todos os setores) }\end{array}$ \\
\hline \multirow{4}{*}{$\begin{array}{l}\text { O } \\
\stackrel{5}{\supset} \\
\text { 口 } \\
0 \\
\alpha \\
\alpha \\
\alpha\end{array}$} & A empresa & 88 & 14 & 145 & 9.036 \\
\hline & Outra empresa do grupo & 19 & 2 & 6 & 483 \\
\hline & $\begin{array}{l}\text { Cooperação com outras } \\
\text { empresas ou instituições }\end{array}$ & 1 & 0 & 6 & 988 \\
\hline & Outras empresas ou instituições & 5 & 15 & 59 & 2.151 \\
\hline \multirow{4}{*}{$\begin{array}{l}0 \\
\text { is } \\
w \\
u \\
u \\
0 \\
\alpha \\
\alpha\end{array}$} & A empresa & 24 & 6 & 13 & 1.932 \\
\hline & Outra empresa do grupo & 6 & 0 & 0 & 209 \\
\hline & $\begin{array}{l}\text { Cooperação com outras } \\
\text { empresas ou instituições }\end{array}$ & 7 & 0 & 4 & 883 \\
\hline & Outras empresas ou instituições & 44 & 9 & 86 & 15.135 \\
\hline
\end{tabular}

Fonte: elaboração a partir de dados do IBGE-PINTEC (2000).

No que tange à implementação de um novo produto, para o segmento de fertilizantes e intermediários, verifica-se uma concentração da responsabilidade em cima da própria empresa ou em alguma empresa do grupo (Tabela 7). Por outro lado, quanto aos defensivos e máquinas agrícolas, há uma maior participação de outras empresas ou instituições na implementação das inovações tecnológicas. Ao analisar a implementação de um novo processo, embora ainda exista uma responsabilidade expressiva das próprias empresas, a participação de outras empresas ou instituições recebe maior destaque.

As atividades inovativas podem ser de dois tipos: (i) pesquisa e desenvolvimento - P\&D (pesquisa básica, aplicada ou pesquisa experimental) e (ii) outras atividades não relacionadas com $\mathrm{P} \& \mathrm{D}$, envolvendo aquisição de bens, serviços e conhecimentos externos (Tabela 8). Quanto à estrutura do financiamento para P\&D e demais atividades inovativas, nota-se que a participação pública é inexistente em de pesquisa e pouco expressiva nas demais atividades. Ao realizar uma comparação com a economia nacional, os segmentos de insumos voltados 
para a agricultura obtiveram, de um lado, percentuais superiores em termos de investimentos privados (próprios e de terceiros) e, por outro lado, percentuais inferiores à média nacional em termos de investimento público. ${ }^{23}$

Assim, pode-se definir a região competitiva e desenvolvida da produção agrícola brasileira como sendo o "polígono dinâmico agroindustrial," ou seja, a macrorregião que vai do Centro-Oeste ao sul do País, envolvendo a parte poente da região Sudeste. No geral, foi este polígono que obteve os melhores indicadores de desenvolvimento das atividades produtoras de grãos bem como maior concentração na produção de insumos tecnológicos. Cabe observar também que as produções do tipo capital intensivo localizaram-se mais neste polígono.

As regiōes mais tradicionais na produção agrícola foram as que apresentaram os menores indicadores de especialização. Entretanto, quanto às novas fronteiras agrícolas, as regiôes são mais especializadas. Quanto à produção de grãos, nota-se que o trigo foi profundamente afetado pela conjuntura externa na década de 1990. Por outro lado, a produção de soja desponta como uma das atividades mais promissoras no Brasil. Já na produção de milho, tem-se uma maior dispersão dessa atividade no âmbito nacional. Por fim, as produções de arroz e feijão têm papel relevante nas regiōes Norte e Nordeste.

\section{Simulação do progresso tecnológico na agricultura: uma análise dinâmica}

Foram estabelecidos até o momento os padrões regionais tanto da produção quanto da tecnologia agrícola. No escopo da avaliação empírica, determinaram-se os comportamentos das atividades e das regióes (ou estados) no contexto das mudanças estruturais brasileiras. Distinguiram-se regiões dinâmicas e passivas em termos de investimentos e de inovações tecnológicas, bem como a especialização das atividades produtivas em termos regionais.

Para estudar no âmbito regional e setorial as trajetórias futuras do comportamento produtivo, a análise requer um método de simulação da dinâmica agrícola no que tange às estratégias de investimentos e às mudanças tecnológicas.

${ }^{23}$ Os investimentos públicos no segmento produtor de insumos são fortemente concentrados no desenvolvimento de sementes. Em fertilizantes, defensivos e máquinas agrícolas, os investimentos dependem mais da própria indústria como de capitais privados. Isto não quer dizer que a participação pública na organização do mercado não seja importante. Pelo contrário, o governo é o responsável pela organização contratual entre os vários agentes, no intuito de reduzir as incertezas no todo da cadeia produtiva e aumentar a eficiência da produção, mesmo que de forma indireta. 
TABELA 8

Empresas que receberam suporte do Governo e estrutura do financiamento das atividades de P\&D e das demais atividades inovativas realizadas pelas empresas, segundo setores selecionados, Brasil, 2000

\begin{tabular}{lcccc}
\hline & Fertilizantes e & Defensivos & Máquinas & Brasil \\
Estrutura do financiamento (\%) & intermediários & agrícolas & e tratores & (todos os setores) \\
\hline
\end{tabular}

É, nesse sentido, que se faz uma ligação da parte empírica com o modelo evolucionário. Assim, o MECA permite explicar a evolução da produção agrícola, comparativamente entre regiōes (dinâmicas e passivas) ou entre agentes econômicos (inovadores e imitadores) de uma mesma atividade.

Diversas simulaçôes foram realizadas para investigar o comportamento da dinâmica competitiva do mercado agrícola e das variáveis e parâmetros especificados no modelo evolucionário de crescimento apresentado no referencial analítico. Por ser um primeiro estudo, os resultados aqui apresentados são preliminares e bastante gerais em termos do que pode ser oferecido pelo modelo. A análise e interpretação das simulaçooes procuram construir uma representação gráfica das trajetórias observadas nas cadeias ${ }^{24}$ produtivas regionais das atividades agrícolas classificadas como comercial e intensiva em capital.

\footnotetext{
${ }^{24} \mathrm{O}$ educated guess utiliza os coeficientes técnicos da soja como representativos das atividades agrícolas comerciais intensivas em capital, definindo as condições iniciais da simulação. Para maiores detalhes, ver Apêndice C.
} 
Nesse sentido, é possível fazer inferências acerca dos comportamentos econômicos da agricultura de mercado em termos industriais, setoriais e regionais. Pretende-se comparar não só as estratégias intrafirmas e seus resultados, mas também a composição do desenvolvimento local, distribuída em regiōes dinâmicas (mais favorecidas em P\&D) e regiōes passivas (menos favorecidas no foco estratégico de desenvolvimento tecnológico). Este tipo de análise só é possível, uma vez que a célula do investimento industrial, no caso a agroindústria, atua em um ambiente localizado e, portanto, tal investimento está associado a um espaço geográfico.

Para tanto, pressupõe-se que as atividades comercial e intensiva em capital são compostas de quatro grupos que se diferenciam apenas na busca por inovação tecnológica. Quanto à estratégia por inovações tecnológicas, as firmas 1 e 2 foram definidas como imitadoras e as firmas 3 e 4 foram consideradas como inovadoras. ${ }^{25} \mathrm{O}$ que as diferencia são os dispêndios temporais com os gastos inovativos. Além do montante dos gastos com inovaçôes tecnológicas, é importante ressaltar que a obtenção de sucesso inovativo correlaciona-se positivamente com os gastos em P\&D.

De acordo com a Tabela 9, seguem-se os valores das variáveis e dos parâmetros iniciais do MECA. No que diz respeito à composição do capital, a especificação foi a de que a depreciação tomava valores extremos. Para o capitalfluxo, esta taxa se aproximou da unidade. Para o capital-estoque, a depreciação foi significativamente mais baixa. Ademais, o modelo trabalha com dois tipos de regimes: (i) quando a firma ou a atividade produtiva regionalizada opta pela inovação e imitação, e (ii) quando a firma opta apenas pela imitação. Em cada caso, "We will consider two different specifications of the distribution from which a firm samples if it has an innovation draw" (Nelson \& Winter,1982:283). Em termos práticos, isto quer dizer que a função de probabilidades para os dois tipos de regimes será diferenciada.

Uma vez definidas as condições iniciais, pode-se perceber que a simulação das trajetórias das atividades produtivas regionais apresenta resultados que se encontram em conformidade com a dinâmica agrícola. Nota-se um aumento da produção agrícola ao longo do tempo. Novos procedimentos tecnológicos

25 É importante observar que a denominação firma depende da unidade de seleção que se queira estudar. Nesse sentido, dependendo do tipo de análise, a unidade de seleção pode ser a própria agroindústria, a atividade agrícola ou mesmo a cadeia produtiva regional. 
TABELA 9

Valores iniciais das variáveis e dos parâmetros do MECA

Indústria, setor ou região nacional - variáveis e parâmetros iniciais

$\begin{array}{lc}\text { Média da produtividade de Ae } & 0,15 \\ \text { Média da produtividade de Af } & 0,25 \\ \text { Coeficiente da demanda } & 475 \\ \text { Efeito aprendizado - b } & 0,01 \\ \text { Depreciação do Ke } & 0,09 \\ \text { Depreciação do Kf } & 0,9 \\ \text { Regime } & 2,0 \\ \text { Banco } & \text { Zero, 1,0 ou 2,5 }\end{array}$

Variáveis e parâmetros iniciais

Firmas, atividades ou regiões constitutivas

\begin{tabular}{lcc}
\hline & 1 e 2 - Imitadoras & 3 e 4 - Inovadoras \\
Produtividade do capital-estoque - Ae & 0,15 & 0,15 \\
Produtividade do capital-fluxo - Af & 0,25 & 0,25 \\
Capital-estoque - Ke & 730 & 730 \\
Capital-fluxo - Kf & 120 & 120 \\
Gasto em inovação - Rin & 0,0 & 0,0223 \\
Gasto em imitação - Rim & 0,00112 & 0,00112 \\
An & 1,25 & 1,25 \\
Am & 0,125 & 0,125 \\
Custo unitário de produção - c & 0,28 & 0,28 \\
Constante de proporcionalidade - $\mathrm{n}$ & 0,27 & 0,27 \\
Coeficiente técnico - $\alpha$ & 6,6 & 6,6 \\
Coeficiente técnico - $\beta$ & 4,0 & 4,0 \\
Relação inicial Kf / Ke - z & 0,16 & 0,16 \\
\hline
\end{tabular}

Fonte: elaboração própria.

foram capazes de elevar a oferta de produtos agrícolas, o que mostra uma tendência de crescimento dessa oferta. Em contraste, observa-se uma tendência declinante do nível de preços, o que também foi observado na análise exploratória de dados. Pode se dizer que, no curto e médio prazo, este diferencial de preços determinará a competitividade da agroindústria juntamente com as estratégias de busca inovativa e os seus custos produtivos. A queda do nível de preços é compatível com a hipótese de elasticidade-preço da procura unitária. Deste modo, o aumento da quantidade física produzida, mantendo-se o valor nominal da 
produção constante, implica a queda do nível de preços. O objetivo primordial é, pois, evidenciar a evolução dos market shares das cadeias produtivas regionais de atividades analisadas.

Em condições padrões, ${ }^{26}$ as firmas inovadoras foram aquelas que se beneficiaram de maiores participaçôes de mercado, tendo um nítido comportamento de aumento da concentração de mercado entre as firmas nas cadeias de produção agrícola, até o período de nove anos (Gráfico 2). Embora tenha ocorrido um favorecimento em termos de market share para as firmas inovadoras, o resultado em termos de lucratividade por unidade de capital mostrou uma leve queda nos primeiros anos; porém, logo em seguida, com uma recuperação dos seus patamares. Em alguns momentos, a lucratividade foi favorável às firmas imitadoras. De uma forma geral, ao se fazer uma interpretação conjunta de participação de mercado versus lucratividade, pode-se dizer que o esforço tecnológico é compensador no tocante à posição de mercado; entretanto, a lucratividade pode não ser uniforme na esperança de que as firmas inovadoras seriam aquelas mais lucrativas, uma vez que o grau de concentração e os respectivos diferenciais de market shares variam ao longo do tempo. Ou seja, apenas para um prazo mais longo as inovaçôes seriam suficientes, dadas as hipóteses iniciais, para beneficiarem expressivamente as firmas inovadoras e até excluírem as firmas menos competitivas. Assim, para um melhor retorno por capital, tanto os gastos em P\&D quanto o financiamento financeiro às inovaçóes teriam de ser muito maiores.

A evolução dos market shares, por sua vez, está associado à concentração de mercado. Verifica-se um relativo aumento da concentração até meados do período. Em contraposição, já na segunda metade do período, observa-se uma diminuição da concentração, dado que o inverso do Índice de Hirschman-Herfindahl foi ascendente ao final do período. Todavia, para simulações com períodos mais longos, a busca inovativa por parte das atividades produtivas regionais propicia uma significativa concentração de mercado, com a exclusão das atividades menos competitivas.

Quanto ao Gráfico 3, apresentam-se as trajetórias das produtividades do capital-estoque e do capital-fluxo. Para ambas as formas de capital, a tendência é ascendente ao longo do período. Entretanto, este movimento é relativamente ${ }^{26}$ Seriam aquelas situações em que os valores atribuídos aos parâmetros e condições iniciais são empiricamente mais
razoáveis, mediante o desempenho do mercado estudado, ou já utilizados em outras simulações. 
GRÁFICO 2

Participação de mercado (market share) das atividades produtivas ao longo do tempo

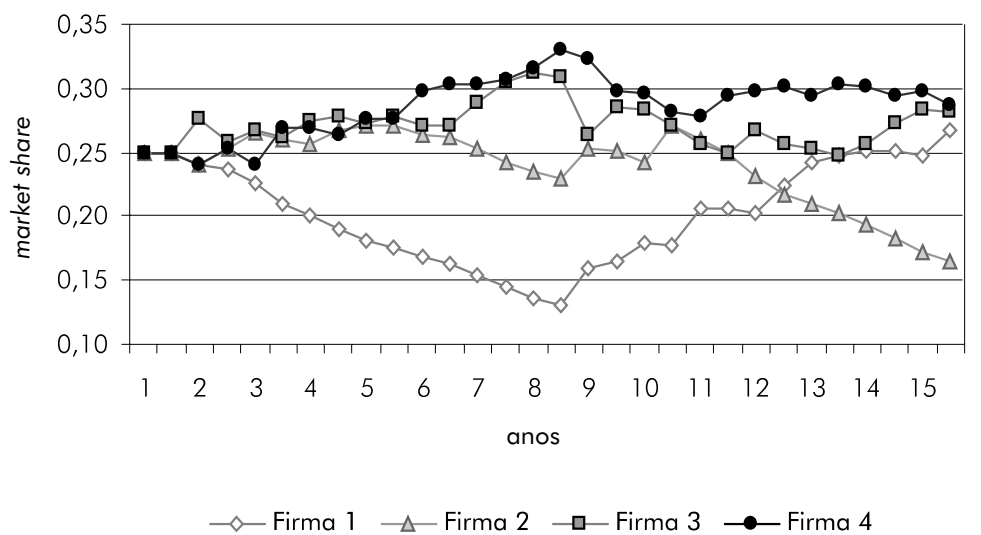

Fonte: elaboração própria.

estável para o capital-fluxo, posto que a sua produtividade já é bastante elevada em comparação à produtividade do capital-estoque. No tocante às firmas imitadoras, o catching up tecnológico se dá por degraus ${ }^{27}$ e o mesmo é incorporado na íntegra, ou seja, ao obter sucesso no processo de imitação, as firmas imitadoras alcançam a produtividade das firmas líderes no mercado. Quando a análise se propuser em diferenciar os tipos de capitais, o capital-fluxo possui uma menor capacidade de obter sucesso nos processos imitativos, enquanto que no capitalestoque a busca por imitação se dá com uma maior freqüência.

Quanto ao volume de capital, há um crescimento descontínuo entre as firmas inovadoras e imitadoras. Para a abordagem de capital-estoque, o comportamento das inovadoras é de aumento do capital em geral, apresentando uma certa estabilidade ao final do período. Por outro lado, nota-se que as firmas imitadoras reduzem gradativamente os seus volumes de capital empregado no processo produtivo. No outro extremo, quanto ao capital-fluxo, há aumento da sua composição tanto nas firmas inovadoras quanto nas firmas imitadoras. Este comportamento já era esperado, uma vez que as firmas buscam compor a melhor proporção entre os fatores produtivos que maximizam a produção e, conseqüentemente, elevam as suas receitas líquidas.

27 Entende-se como sendo o efeito do aprender-fazendo (learning by doing). 
GRÁFICO 3

Produtividade da agroindústria ao longo do tempo para distintos tipos de capital (Estoque e Fluxo)
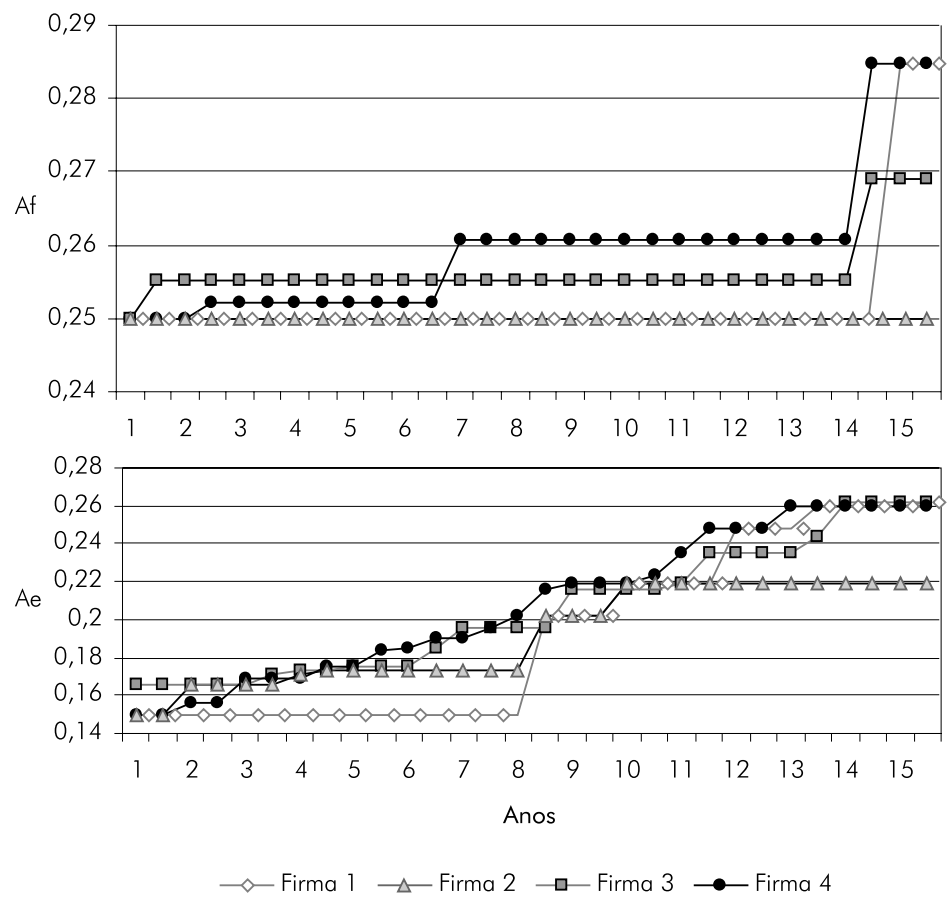

Fonte: elaboração própria.

De acordo com o Gráfico 4, representação síntese de toda a contribuição do MECA, a relação entre capital-fluxo e capital-estoque aumenta ao longo do tempo, variando em um intervalo constituído de dois raios limites, respectivamente $0,11\left(R_{1}\right)$ a $0,3\left(R_{2}\right)$. Tanto a elevação da composição de capital-fluxo quanto o aumento contínuo da relação entre os insumos produtivos foram conseqüências da maior produtividade do capital. Nesse sentido, os agentes econômicos procuram intensificar o uso do fator mais produtivo, que no caso é representado pelo capital-fluxo. Todavia, ao longo do período, a produtividade do capital-fluxo não possui a mesma dinâmica de crescimento. É importante ressaltar que, para simulaçóes com períodos mais amplos, a tendência será a de que haja uma recomposição do capital-estoque, fazendo com que o caminho de expansão da produção volte em direção à relação inicial de capital-fluxo sobre capital-estoque. Para o caso agrícola, a produção é determinada pela combinação 
GRÁFICO 4

Caminho de expansão na agricultura para uma função de produção de proporções fixas em uma situação dinâmica limitada para um período de 15 anos

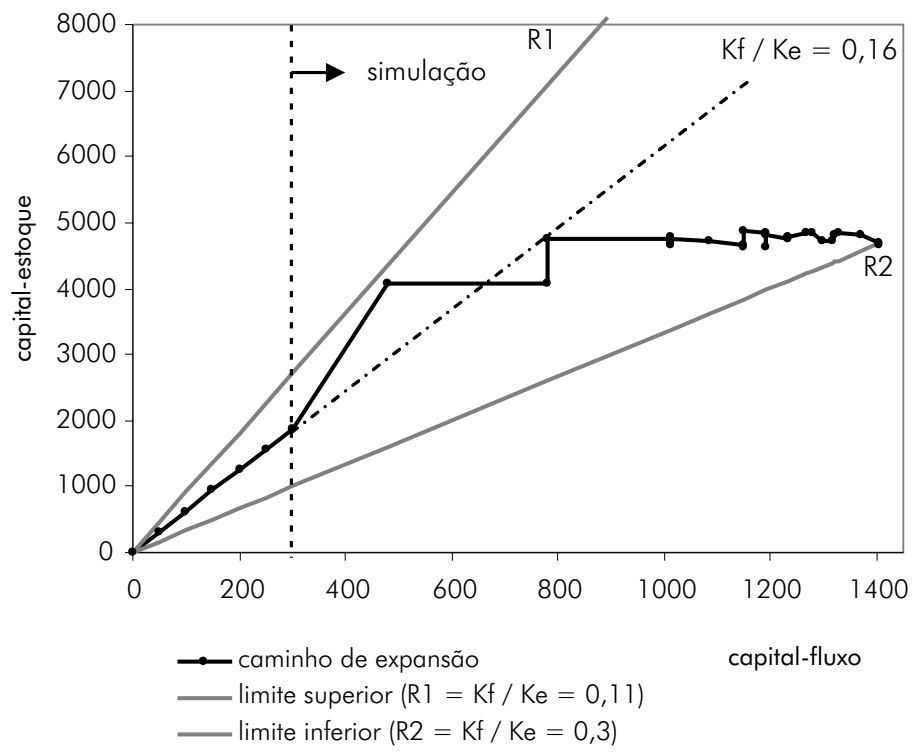

Fonte: elaboração própria.

mínima dos capitais (estoque e fluxo), já que seria impossível a produção agrícola com apenas um único tipo de capital. A substituição do capital-estoque por capital-fluxo se dá de forma parcial, uma vez que, no longo prazo, é necessário obter progresso tecnológico no capital como um todo. Assim, a combinação mínima de capital é aquela que maximiza não só a produção, mas também a produtividade agrícola. Em períodos mais longos, o modelo mostra que a combinação de capital-estoque com capital-fluxo tende ao equilíbrio inicial, mesmo que haja uma variação interna a dois limites produtivos.

Como no modelo seminal, o MECA pode fazer alguns tipos de predições mediante determinadas estruturas de concorrência. Quando não houver buscas inovativas em P\&D e a produtividade do capital for mantida constante para todas as firmas, a dinâmica do modelo torna-se determinística, repartindo o mercado em fatias idênticas. É preciso, portanto, que a simulação possua uma 
situação mais complexa, ou seja, quando há diferenciação nas estratégias competitivas, ou por buscas de aumentos da produtividade ou por custos diferenciados. Assim, as atividades agroindustriais com custos relativos mais baixos e com maiores ganhos de produtividade podem eliminar as atividades marginais do mercado.

Supondo que as firmas não realizam inovações ou que as despesas inovativas são nulas $\left(r_{i n}=0\right.$, para todo $i$ e em todo o período) e que as firmas imitadoras investem o mesmo volume em gastos inovativos $\left(r_{i m}\right.$ sendo um valor positivo e constante para todas as firmas), as atividades agroindustriais que sobrevivem terão a mesma produtividade, que coincide com a produtividade máxima e que associa com a melhor tecnologia empregada. Em suma, na ausência de progresso tecnológico, a estrutura de mercado é determinada pelo comportamento imitativo e pela dinâmica da difusão do conhecimento.

Além disso, o modelo permite a simulação de ambientes com diferenciados regimes de financiamentos, um mais restrito e outro mais amplo. A partir do momento que as empresas podem adquirir maiores volumes de empréstimos financeiros, a busca por melhores técnicas aumenta ao longo do tempo. Por outro lado, caso não haja financiamento externo às firmas, as oportunidades tecnológicas dependerão de um desempenho favorável da margem de lucro por unidade de capital e, nesse caso, as firmas terão comportamentos menos oportunistas. Isto quer dizer que o financiamento das inovações será através da geração interna de recursos pelas firmas. Enfim, o MECA procura estabelecer o alicerce para a discussão neo-schumpeteriana na agricultura. Desta forma, estruturas de mercado mais concentradas geram produtividades mais elevadas e, conseqüentemente, maiores retornos financeiros. A questão tecnológica na agricultura é também uma variável-chave para o crescimento econômico.

\section{Conclusão}

O esforço teórico proposto por este artigo visou, em primeiro lugar, inserir os debates de economia agrícola sob o enfoque da teoria evolucionária do crescimento econômico. Em segundo lugar, procurou-se construir um modelo de evolução agrícola e comparar os seus resultados com os padrões regionais dos sistemas agroindustriais brasileiros produtores de grãos. Para tanto, foi preciso 
desvencilhar-se dos pressupostos clássicos arraigados na maioria dos estudos agrícolas. O referencial teórico utilizado baseou-se nas pressuposições de incertezas do ambiente, na racionalidade limitada dos agentes, no desequilíbrio dinâmico e instabilidade estrutural, bem como em aspectos essenciais à competição schumpeteriana e às mudanças endógenas da tecnologia no processo produtivo. A inovação tecnológica cresce com o tamanho dos sistemas ou complexos agroindustriais regionais e com a concentração de mercado.

Quanto ao método de análise regional, conforme a Figura 2, foi possível identificar o polígono dinâmico agroindustrial, como sendo a região que concentra mais de $90 \%$ da produção de grãos e dos insumos tecnológicos voltados para a agricultura. No que se refere à produção de grãos, há um desempenho favorável da soja no Centro-Oeste e do café e do feijão no Sudeste. Observase também uma maior diversificação produtiva no Sul do País. Pode-se dizer, então, que a competição por recursos produtivos nos sistemas agroindustriais (cadeias produtivas) leva à busca permanente de inovaçôes tecnológicas, caracterizando uma dinâmica evolucionária de crescimento produtivo e concentração setorial e regional.

Por fim, para a construção do MECA, foi necessário, de um lado, definirse uma nova concepção do capital, a qual representa características centrais da interpretação do processo produtivo agrícola. De outro, para conciliar a nova concepção, trabalhou-se com uma função de produção de proporções fixas em uma situação dinâmica limitada. $\mathrm{O}$ capital na agricultura está dividido em dois tipos: (i) capital-estoque, e (ii) capital-fluxo. O primeiro com menor taxa de depreciação já é bem definido na economia (como visto, representado pelas benfeitorias, máquinas e equipamentos agrícolas). No outro extremo, o segundo é quase que inteiramente consumido no processo produtivo em um dado período de plantio e colheita (representado pelos defensivos, fertilizantes e sementes).

Quanto à função de produção, trabalha-se com o mínimo da combinação entre os dois tipos de capital que maximiza a produção. É impossível aumentar a produção com apenas um tipo de capital. Assim, a combinação mínima é pré-requisito para o processo produtivo no caso agrícola. Diante de uma situação limitada, não há como aumentar a produção substituindo-se continuamente um capital pelo o outro. O modelo mostra que, em um ambiente de competição tecnológica, sobrevivem às cadeias produtivas mais inovadoras em 
FIGURA 2

Polígono dinâmico agroindustrial do Brasil - 1990 a 2002

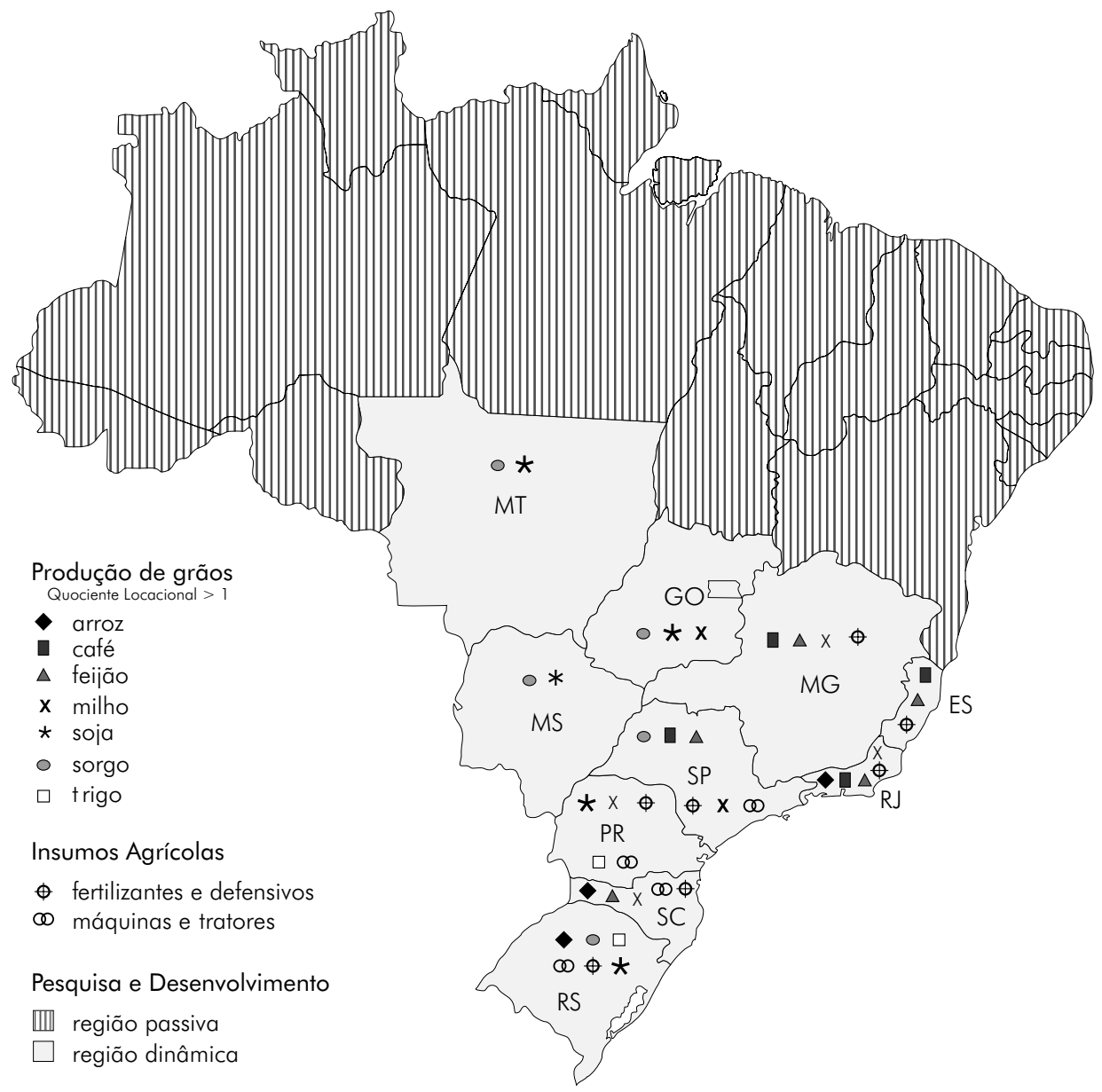

Fonte: elaboração própria.

detrimento da marginalização das imitadoras, elevando assim as participações de mercado e, conseqüentemente, os lucros de monopólios. Na ausência de mudanças tecnológicas, o agronegócio caminharia em direção a um equilíbrio estático, no qual a participação de mercado e a taxa de lucro tenderiam à equalização entre as firmas.

Nesse sentido, definindo as atividades agrícolas como um conjunto processador de tecnologia no espaço econômico e geográfico, percebe-se que o 
aumento produtivo regional é determinado de forma endógena pelas mudanças tecnológicas, em que produtores inovadores estarão sempre em posições vantajosas, em termos de lucratividade, quando comparados aos imitadores. Se a expectativa é de uma redução dos níveis de preço, não há porquê se elevar à quantidade ofertada. De fato, a oferta agrícola aumenta mediante a introdução de novas tecnologias, as quais reduzem os custos de produção e sustentam as remuneraçôes dos produtores. Enfim, embora ainda preliminares, os resultados do modelo estabelecem as bases para discussão do paradigma evolucionário inserido no contexto agrícola.

\section{Referências bibliográficas}

AGRIANUAL - Anuário da Agricultura Brasileira, São Paulo: FNP, 2002.

Albuquerque, E. M., "Immature Systems of Innovation: Introductory Notes About a Comparison Between South Africa, India, Mexico and Brazil Based on Science and Technology Statistics", in Conferência Internacional de Sistemas de Inovação e Estratégias de Desenvolvimento para o Terceiro Milênio, 2003, Rio de Janeiro. Anais... Rio de Janeiro: UFRJ/IE, 2003. CD-ROM.

Binger, B.R.; Hoffman, E., Microeconomics with Calculus, 2.ed., Nova York: Addison-Wesley, 1998.

Burnham, T. C., Essays on Genetic Evolution and Economics, Cambridge, Massachusetts: Harvard University, 1997. (Tese de Doutorado).

Cavalcanti Filho, P. F. M. B., Ciclo Econômico e Instabilidade Estrutural: um modelo evolucionário multissetorial Minsky-Keynes-Schumpeteriano, Rio de Janeiro: IE-UFRJ, 2002. (Tese de Doutorado)

Cerqueira, H.E.G., Economia Evolucionista: um capitulo sistêmico da teoria econômica?, Belo Horizonte: UFMG/CEDEPLAR, 27p., 2000 (Texto para Discussão, 150).

Crocco, M. A., Uncertainty, Technical Change and Effective Demand, Londres: University of London, 1999, (Tese de Doutorado). 
Desmond, A.; Moore, J., Darwin: a Vida de um Evolucionista Atormentado, 3.ed., São Paulo: Geração Editorial, 2000.

Dosi, G.; Egidi, M., "Substantive and Procedural Uncertainty", in Journal of Evolutionary Economics, n.1, abr., p.145-168, 1991.

Dosi, G.; Freeman, C.; Nelson, R.; Silverberg, G.; Soete, L., Technical Change and Economic Theory, Londres: Pinter Publishers, 1988.

Dosi, G., Innovation, Organization and Economic Dynamics: Selected Essays, Cheltenham, UK: Edward Elgar, 2000.

, Technical Change and Industrial Transformation, Nova York: St. Martin's Press: 1984.

Ferguson, C. E., Microeconomic Theory, 3.ed. Homewood/Illinois: Richard D. Irwin, 1972.

Food and Agriculture Organization of the United Nations - FAO. Statistical Databases (vários anos). [s.l.], 2003. Disponível em: http://www.fao.org.

Foss, N. J., "Why Transaction Cost Economics Needs Evolutionary Economics, in Revue D'économie Industrielle, [s.1.], n.68, p.7-25, 1994.

Gujarati, D. N., Econometria Básica, 3.ed., São Paulo: Makron Books, 2000.

Haddad, P. R., "Medidas de Localização e de Especialização", in Haddad, P. R.; Ferreira, C. M. C.; Boisier, S.; Andrade, T. A., Economia Regional: teorias e métodos de análise, Fortaleza: Banco do Nordeste, p.225-245, 1989.

Instituto Brasileiro de Geografia e Estatística - IBGE, Levantamento Sistemático da Produção Agrícola - LSPA, Pesquisa Industrial Anual - PIA, Pesquisa Industrial de Inovação Tecnológica - PINTEC, Produção Agrícola Municipal - PAM (tabulaçōes especiais - vários anos). Rio de Janeiro, 2003.

Isard, W., Methods of Regional Analysis: an introduction to regional science, Cambridge: MIT Press, cap.5, p.122-181. cap.7, p.232-308, 1960.

Kon, A., Economia Industrial, São Paulo: Nobel, 1999.

Lott Jr., J. R. (org.), Uncertainty and Economic Evolution: essays in honor of Armen A. Alchian, Londres: Routledge, 1997.

Metcalfe, J. S., Ramlogan, R., Uyarra, E., "Economic Development and the Competitive Process", in Conferência Internacional de Sistemas de Inovação e Estratégias de Desenvolvimento para o Terceiro Milênio, 2003, Rio de Janeiro. Anais... Rio de Janeiro: UFRJ/IE, 2003. CD-ROM. 
Nelson, R. R.; Winter, S., An Evolutionary Theory of Economic Change, Cambridge, Mass.: Harvard University Press, 1982.

Pavitt, K., "Sectoral Patterns of Technical Change: Towards a Taxonomy and a Theory, in Research Policy, n.13, p.343-373, 1984.

Possas, M. L.; Koblitz, A.; Licha, A.; Oreiro, J. L.; Dweck, E., "Um Modelo Evolucionário Setorial", in Revista Brasileira de Economia, Rio de Janeiro, v.3, p.333377, jul./set. 2001.

Possas, M. L., "Concorrência Schumpeteriana", in Kupfer, D.; Hasenclever, L. (orgs.), Economia Industrial: fundamentos teóricos e práticas no Brasil, Rio de Janeiro: Campus, cap.17, p.415-429, 2002a.

"Elementos para uma Integração Micro-macrodinâmica na Teoria do Desenvolvimento Econômico", in Revista Brasileira de Inovação. Rio de Janeiro, v.1, n.1, p.123-149, jan./jun. 2002b.

Saviotti, P.; Metcalfe, J. S., Evolutionary Theories of Economic and Technological Change: present status and future prospects, Londres: Harwood University Press, 1991.

Schumpeter, J. A., História da Análise Econômica, v.2, São Paulo: Fundo de Cultura, 1964.

Sicsú, A. B.; Lima, J. P. R., "Fronteiras Agrícolas no Brasil: a lógica de sua ocupação recente", in Nova Economia, Belo Horizonte, v.10, n.1, p.109-138, jul., 2000.

Solow, R. M., "Technical Change and the Aggregate Production Function, in Lindauer, J. (org.). Macroeconomic Readings, USA: The Free Press/ Macmillan, p.71-179, 1968.

Valente, M., Evolutionary Economics and Computer Simulation: a model for the evolution of markets, Dinamarca: University of Aalborg, 3v., 1999. (Tese de Doutorado)

Vieira Filho, J. E. R., Abordagem Evolucionária da Dinâmica do Setor Agricola, Viçosa: UFV, 2004. (Dissertação de Mestrado)

Williamson, O. E., "The Logic of Economic Organization", in Williamson, O. E.; Winter, S.G. (orgs.). The Nature of the Firm: origins, evolution, and development, Nova York: Oxford University Press, cap.7, p.90-116, 1993. 


\section{Apêndice A}

\section{Função de produção com proporções fixas para o MECA}

A função de produção procura descrever a relação entre os insumos utilizados no processo produtivo e o produto resultante do processamento desse processo. Para simplificar, adota-se a premissa de que há apenas dois insumos produtivos: capital-estoque e capital-fluxo. Além disso, a curva que representa o conjunto de todas as combinações possíveis de insumos que resultam no mesmo volume de produção é denominada de isoquanta. As isoquantas são classificadas conforme a quantidade de produto que podem gerar para uma dada combinação de insumos. Nesse sentido, as isoquantas são determinadas pela variável tecnológica.

Numa função de produção de proporçôes fixas (Figura A1) tem-se o mapa de isoquantas. Nesse tipo de função de produção, a quantidade produzida é determinada por uma combinação específica de insumos, a qual não pode ser alterada. A função de produção com isoquantas em forma de "L" possui Taxa Marginal de Substituição Técnica igual a zero, de tal modo que apenas uma combinação de capital-estoque e capital-fluxo pode ser empregada para produ-

FIGURA A1

Mapa de isoquantas na agricultura para uma função de produção com proporções fixas

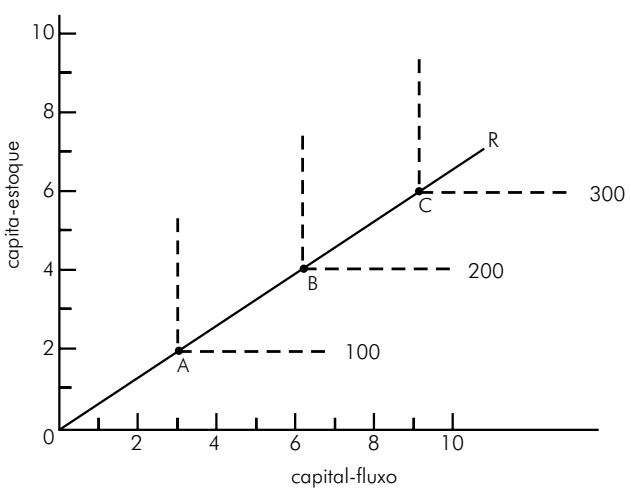

Fonte: elaboração própria. 
zir cada nível de produto. Se o capital-estoque estiver constante e o capitalfluxo aumentar, o nível de produção não muda. Em outras palavras, o produto marginal de aumento de apenas um dos insumos é igual a zero. É impossível a substituição entre os insumos. Um raio partindo da origem e coincidindo com os vértices de cada isoquanta define uma específica taxa de insumos (constante). Movimentos ao longo do raio mostram diferentes níveis de produto e taxas de insumos constantes. Nos pontos A, B e C, a proporção de utilização de insumos é uma constante de 2:3; porém, o nível de produto varia de 100, 200 e 300, respectivamente.

Num caso mais realista, pode-se trabalhar com uma situação em que existe mais de uma combinação de proporções fixas entre os insumos para um mesmo nível de produção. Conforme a Figura A2, cinco proporções distintas de combinação de insumos podem gerar o mesmo nível de produto igual a 100. Notase que, diferentemente de uma isoquanta que permite a substituição de fatores, entre os pontos A e B, por exemplo, não é possível aumentar a produção. Entretanto, se as unidades de insumos são suficientemente divisíveis, é permitido produzir com duas proporções fixas de fatores simultaneamente.

Por exemplo, suponha que a produção desejada seja a obtenção de 100 unidades de produto com a utilização de 7,25 de capital-estoque e 2,5 unidades

FIGURA A2

Mapa de isoquantas na agricultura quando cinco processos de proporções fixas são analisados

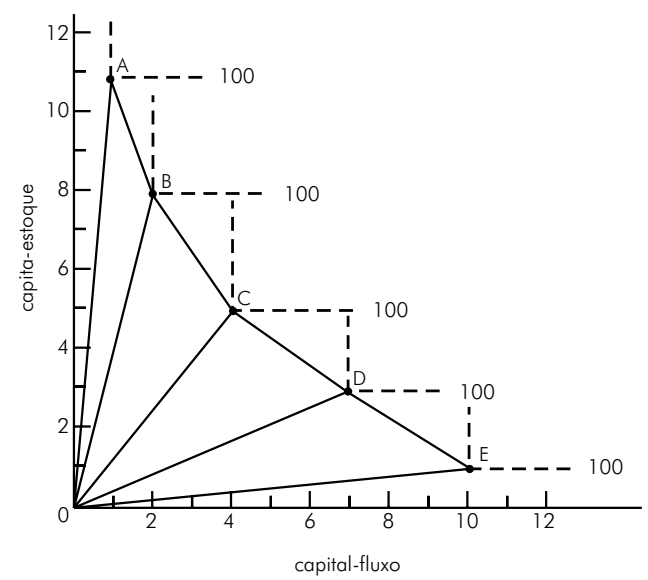

Fonte: elaboração própria. 
de capital-fluxo. Pode-se produzir 75 unidades de produto por uma proporção de insumos representada pelo raio OB e 25 unidades pela proporção OC. De um lado, para produzir 75 unidades a uma taxa de 8:2, seriam requeridas seis unidades de capital-estoque e 1,5 unidade de capital-fluxo. Por outro, para produzir 25 unidades a uma taxa de 5:4, seriam necessários à utilização de 1,25 unidade de capital-estoque e 1,0 unidade de capital-fluxo. Então, 100 unidades de produto poderiam ser produzidas a uma taxa desejada de 7,25:2,5 por uma combinação de dois processos representados pelos raios OB e OC, ou seja, uma situação intermediária entre B e C.

Finalmente, para conciliar a idéia da função de produção com proporções fixas juntamente com o caráter dinâmico das transformações econômicas ao longo tempo, especifica-se a Figura A3, a qual representa o caminho de expansão da produção de uma situação hipotética que limita a variabilidade da combinação das proporções de fatores produtivos na agricultura por meio de dois raios OR1 e OR2. Nos pontos A, B e C a relação de insumos utilizados na produção varia ao longo do tempo. Todavia, a substituição de fatores produtivos se restringe a um limite superior e a um inferior, podendo compatibilizar as isoquantas de bico com o caráter evolucionário das transformaçôes tecnológicas no decorrer do período.

FIGURA A3

Mapa de isoquantas na agricultura para uma função de produção de proporções fixas em uma situação dinâmica limitada

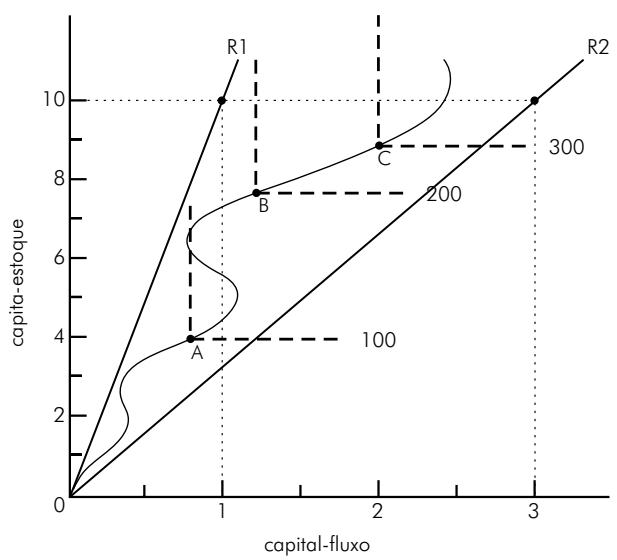

Fonte: elaboração própria. 


\section{Apêndice B}

\section{Curva de demanda com elasticidade unitária}

A curva de demanda inversa pode ser descrita como sendo o preço função da quantidade. Tem-se:

$$
p=F(q), \quad F^{\prime}(q)=\frac{d p}{d q}<0
$$

A receita total é dada pelo produto do preço pela quantidade,

$$
R T=p \cdot q=q \cdot F(q)
$$

e a receita marginal é

$$
R m g=\frac{d[q \cdot F(q)]}{d q}=F(q)+q \cdot F^{\prime}(q)=p+q \cdot \frac{d p}{d q}
$$

Colocando o preço em evidência no lado direito da equação (3):

$$
R m g=p \cdot\left(1+\frac{q}{p} \frac{d p}{d q}\right)
$$

Por definição, a elasticidade preço da demanda é

$$
\eta=-\frac{d q}{d p} \frac{p}{q}
$$

Substituindo a equação (5) na equação (4), apresenta-se a equação da receita marginal relacionada com a elasticidade preço da demanda:

$$
R m g=p \cdot\left(1-\frac{1}{\eta}\right)
$$

Quando a elasticidade da demanda é constante ao longo de toda a curva da demanda, diz-se que a curva é isoelástica. A Figura B1 mostra uma curva de demanda com essa propriedade. 
Se a curva de demanda tem elasticidade unitária, a receita marginal é zero e, portanto, a receita total é constante. Uma redução do preço, por exemplo, ocasionaria um aumento da quantidade demandada, mas de tal forma que o aumento fosse suficiente para deixar o gasto total inalterado. De forma algébrica, se $\eta=1$, então $R m g=0$ e a $R T=c$, onde $c$ é uma constante.

FIGURA B1

Curva de demanda de elasticidade unitária

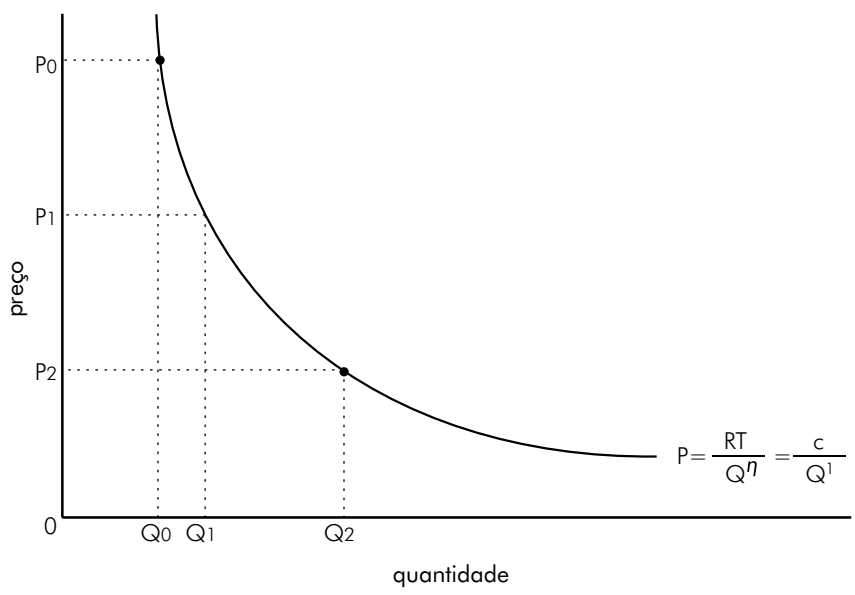

Fonte: elaboração própria. 


\section{Apêndice $C$}

\section{Coeficientes técnicos e condições iniciais da simulação}

No que tange aos custos de produção da soja (dólares por hectare) da safra de 2000/01, conforme o Tabela C1, tem-se a receita igual a 475 dólares, valor este que definirá a receita total no MECA. No que se refere às operações relativas ao serviço do capital-estoque, o custo é mensurado em média por 73 dólares. Se a depreciação do capital-estoque é definida com base em dez anos, o valor total do capital-estoque é dado por 730 dólares. Por outro lado, o custo referente ao capital-fluxo é calculado em cerca de 120 dólares. A relação de capital-fluxo (120) por capital-estoque (730) determina a relação inicial no disparo do modelo.

Deve-se ressaltar que a constante de proporcionalidade é determinada de forma arbitrária $(0,27)$, no intuito de manter uma força centrípeta em torno da relação inicial entre os capitais $(0,16)$ e definir uma restrita (ou limitada) substituição de fatores produtivos no mapa de isoquantas. Tal constante de proporcionalidade é necessária, uma vez que o modelo roda em paralelo tanto para o capital-estoque quanto para capital-fluxo. Quanto aos coeficientes técnicos, a relação entre a receita total (475) e os respectivos custos anuais de capitais (120 para o capital-fluxo e 73 para o capital-estoque), é possível determinar $\beta$ igual a 4 e $\alpha$ igual a 6,6. A produtividade respectiva de cada capital é o inverso dos coeficientes técnicos.

Por fim, a composição total de capital é dada pela soma do capital-fluxo e do capital-estoque, sendo mensurado por um valor de 850 dólares. Como o custo total de produção é dado por 246 dólares em média, o custo unitário de produção é dado pela relação entre o custo total e a composição total de capital $(0,28)$. Quanto aos gastos de inovação e imitação, os seus parâmetros foram retirados do modelo Nelson e Winter (1982), por serem valores já testados empiricamente. Diante do exposto, foi possível definir, de forma razoável, não só os coeficientes técnicos dos capitais na agricultura, como também as condições iniciais do modelo. 
José Eustáquio Ribeiro Vieira Filho, Antônio Carvalho Campos, Carlos Maurício de Carvalho Ferreira

TABELA C 1

Custo da produção de soja - safra 2000/01 (US\$/ha)

\begin{tabular}{|c|c|c|}
\hline Compatibilidade no MECA & Descrição & Valor \\
\hline Serviço do capital-estoque & Operações (A) & 72,75 \\
\hline Capital-fluxo & Insumos (B) & 119,68 \\
\hline Demais custos & Administração (C) & 29,86 \\
\hline & Pós-colheita (D) & 23,29 \\
\hline Custo total & Custo total $(A+B+C+D)$ & 245,57 \\
\hline Receita total & Receita & 475,00 \\
\hline Região de referência & & Paraná \\
\hline
\end{tabular}

Fonte: elaboração a partir de dados do AGRIANUAL (2002). 